1353541

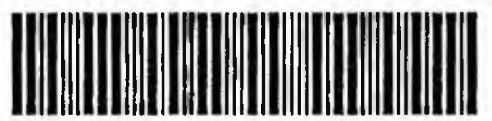

UNIVERSITY OF SURREY LIBRARY 


\section{All rights reserved}

\section{INFORMATION TO ALLUSERS}

The quality of this reproduction is dependent upon the quality of the copy submitted.

In the unlikely event that the author did not send a complete manuscript and there are missing pages, these will be noted. Also, if material had to be removed, a note will indicate the deletion.

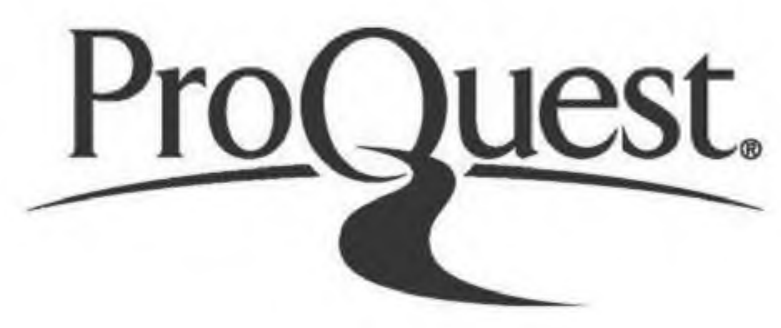

Published by ProQuest LLC (2017). Copyright of the Dissertation is held by the Author.

All rights reserved.

This work is protected against unauthorized copying under Title 17, United States Code Microform Edition (c) ProQuest LLC.

ProQuest LLC.

789 East Eisenhower Parkway

P.O. Box 1346

Ann Arbor, MI 48106-1346 

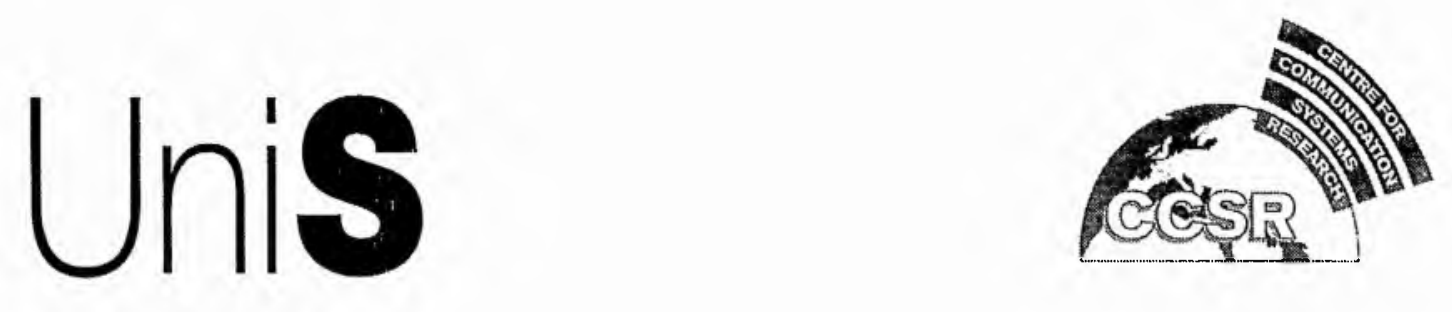

\title{
ATM ON-BOARD SATELLITE CONGESTION CONTROL FOR MULTIMEDIA SERVICES
}

\author{
by \\ Jong ok Joo \\ Supervised by \\ Dr. Rahim Tafazolli
}
Thesis submitted to University of Surrey
for the degree of
Master of Philosophy

Centre for Communications Systems Research
University of Surrey

JULY 1999 


\section{CONTENTS}

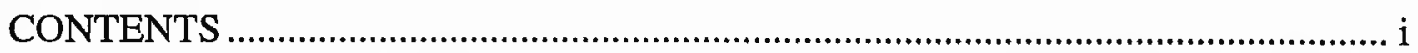

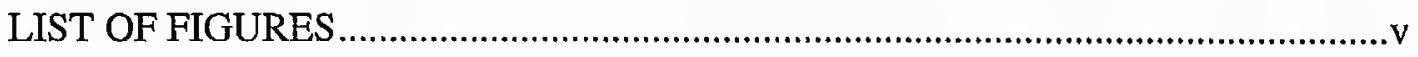

LIST OF TABLES.

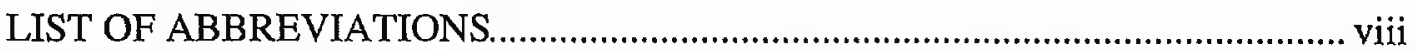

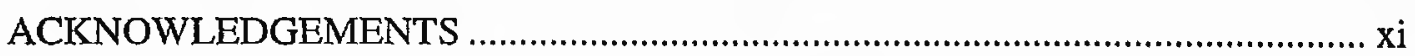

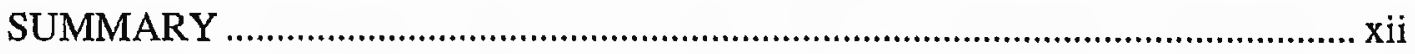

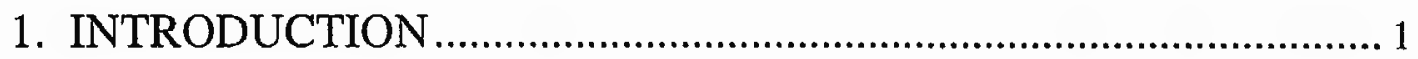

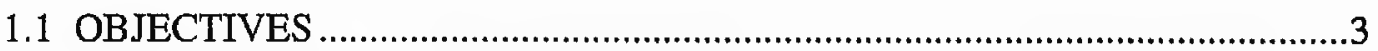

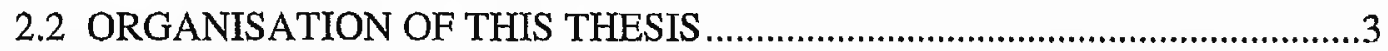

2. REVIEW ATM STRUCTURE AND FUNCTIONS ........................... 4

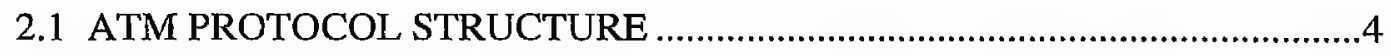

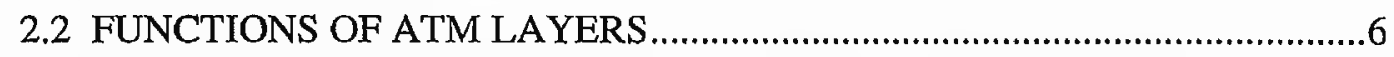

2.2.1 THE PHYSICAL LAYER...........................................................................6

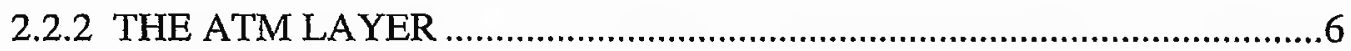

2.2.3 THE ATM ADAPTATION LAYER(AAL) …………...............................

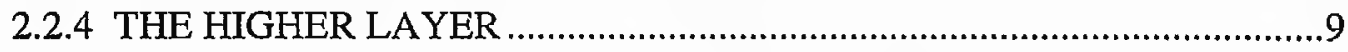




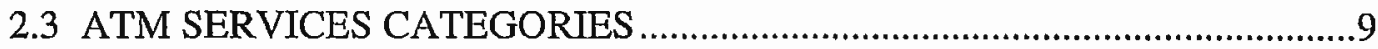

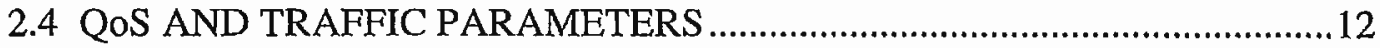

2.4.1 QUALITY OF SERVICE PARAMETERS ........................................ 12

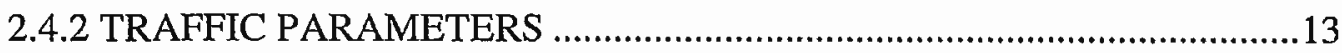

2.4.3 PEAK CELL RATE(PCR) CONFORMANCE.......................................14

2.4.4 SUSTAINABLE CELL RATE(SCR) CONFORMANCE.........................15

3. CONGESTION CONTROL IN ATM NETWORKS .......................18

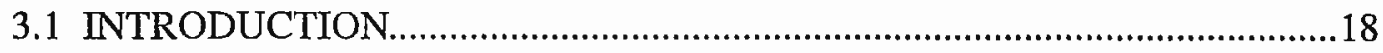

3.2 THE ABR TRAFFIC MANAGEMENT .............................................21

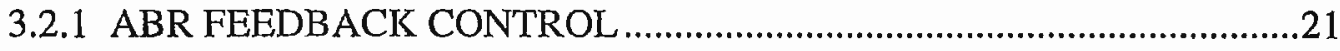

3.2.2 RESOURCE MANAGEMENT CELL...............................................22

3.2.3 SOURCE, DESTINATION AND SWITCH RULES ............................26

3.3 CONVENTIONAL CONGESTION CONTROL SCHEMES........................30

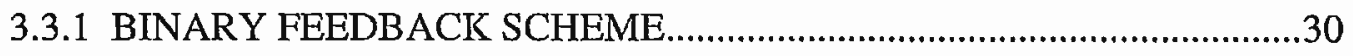

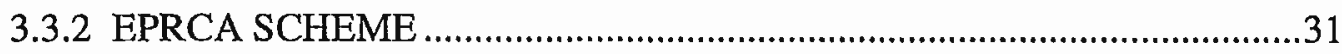

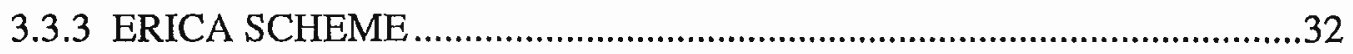

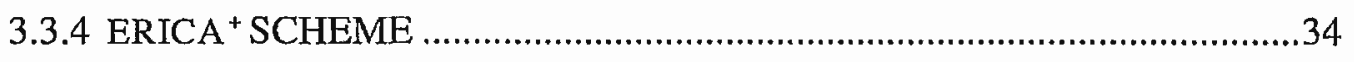

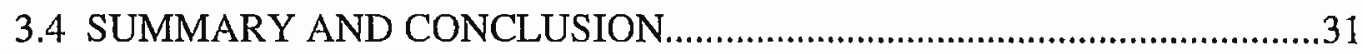

4. CONGESTION CONTROL FOR ON-BOARD ATM SWITCH IN

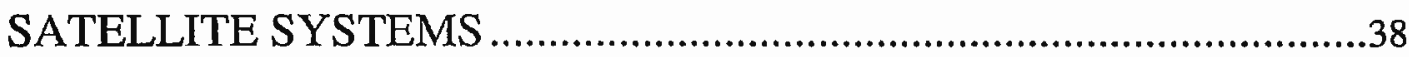

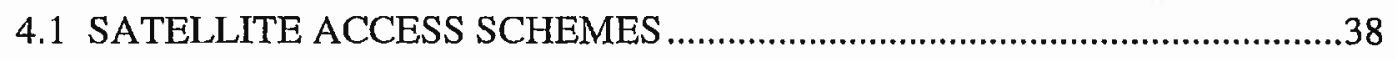

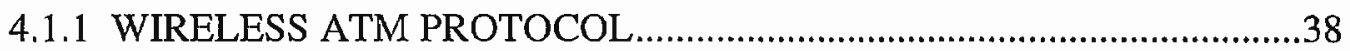




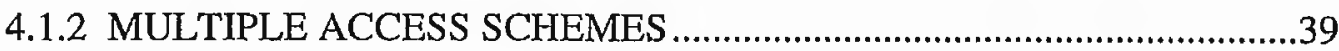

4.1.3 WMAC PROTOCOL ARCHITECTURES..........................................43

4.2 SATELLITE-ATM SYSTEM MODEL ANALYSIS....................................44

4.2.1 SATELLITE FEEDBACK CONTROL SCHEME ...................................44

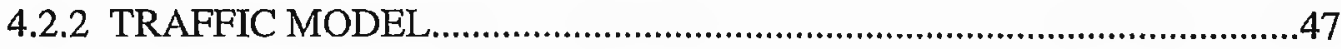

4.2.3 PROPOSED CONGESTION CONTROL SCHEME .............................52

4.3 SUMMARY AND CONCLUSION..........................................................52

5. SIMULATION MODELLING AND RESULTS ............................. 54

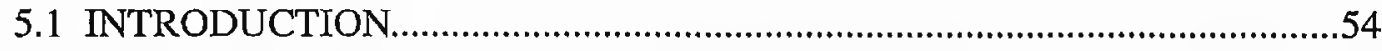

5.2 SIMULATION MODEL PARAMETERS …...................................................55

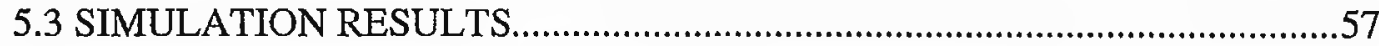

5.3.1 EFFECT OF TRAFFIC PRIORITY, UTLISATION

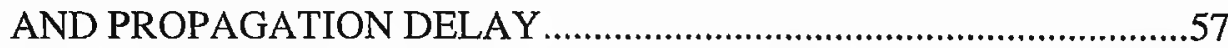

5.3.2 EFFECT OF SOURCE BEHAVIOUR ..............................................60

5.3.3 EFFECT OF THE CONGESTION CONTROL FUNCTION....................63

5.3.4 EFFECT OF THE CONTROL TIME INTERVAL, INCREASE

AND DECREASE FACTORS .....................................................67

5.4 FEATURES OF THE SUGGESTED CONGESTION CONTROL

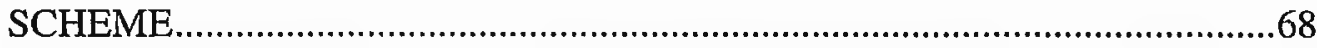

6. CONCLUSIONS AND FUTURE STUDY 


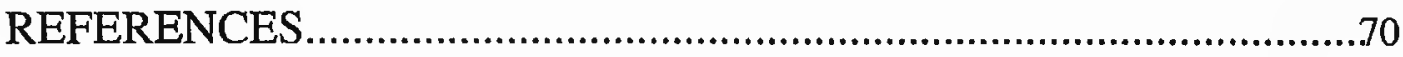

APPENDIX-A : SOURCE, DESTINATION AND SWITCH BEHAVIOUR IN ATM TRAFFIC MANAGEMENT .............................................................................73

APPENDIX-B : MARKOV MODULATED FLUID FLOW MODEL AND

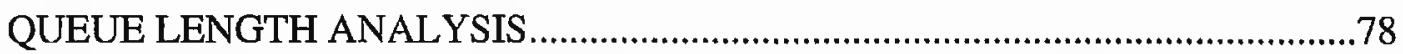




\section{LIST OF FIGURES}

Figure Number

Page

Figure 2-1 : Reference Model of BISDN Protocol 5

Figure 2-2: An ATM Network Interface 5

Figure 2-3 : Cell Header for User-to-Network Interface(UNI) 7

Figure 2-4 : Data Units in ATM Protocol 8

Figure 2-5 : ATM Network and Its Service Categories 9

Figure 2-6 : PCR Reference Model 14

Figure 2-7 : SCR Reference Model 16

Figure 3-1 : Segmented Feedback Control 20

Figure 4-1 : Dynamic TDMA WMAC Frame Format 36

Figure 4-2 : WATM Protocol Architecture $\quad 37$

Figure 4-3 : A Simple Satellite System Model 39

Figure 4-4 : On-board Traffic Model 42

Figure 4-5 : Bursty Source Behaviour 43

Figure 4-6: The Relationship between Q1 and Rd 47

Figure 4-7: On-board Switch Behaviour $\quad 48$

Figure 4-8: No Congested State $\quad 50$

Figure 4-9: Congested State 51

Figure 5-1 : Simulation Configuration $\quad 54$

Figure 5-2 : End-to-End Delay (Zero Propagation Delay) 57

Figure 5-3 : End-to-End Delay (Propagation Delay : 50ms) 58

Figure 5-4 : End-to-End Delay (Propagation Delay :125ms) 58

Figure 5-5 : Queue Length (Zero Propagation Delay) 59

Figure 5-6 : Queue Length (Propagation Delay : 50ms) 59

Figure 5-7 : Queue Length (Propagation Delay : 125ms) 60

Figure 5-8 : Burstiness \& ABR End-to-End Delay(Propagation Delay : 50ms) 61 
Figure 5-9 : Burstiness \& ABR End-to-End Delay(Propagation Delay : 125ms) 61

Figure 5-10 : Burstiness \& Queue Length (Propagation Delay : 50ms) 62

Figure 5-11 : Burstiness \& Queue Length (Propagation Delay : 125ms) 62

Figure 5-12: Queue Length with the New Control Function 63

Figure 5-13: Queue Length (Offered Load : 0.6) 64

Figure 5-14 : Queue Length (Offered Load : 0.9) 64

Figure 5-15 : ABR Input Rate (Offered Load : 0.6) 65

Figure 5-16 : ABR Input Rate (Offered Load : 0.9) 66

Figure 5-17 : The Relationship between Response Time and Control Parameters 67 


\section{LIST OF TABLES}

Table Number

Page

Table 2-1 : ATM Attributes for Service Categories

Table 3-1 : Resource Management Cell Format

Table 3-2: Floating Point Bit Position for the Two Bytes RM Cell Rate Fields

Table3-3 : ACR Up-date Values

Table 5-1 : Simulation Parameters 


\section{LIST OF ABBREVIATIONS}

$\begin{array}{ll}\text { AAL } & \text { ATM Adaptation Layer } \\ \text { ABR } & \text { Available Bit Rate } \\ \text { ACR } & \text { Allowed Cell Rate } \\ \text { ATM } & \text { Asynchronous Transfer Mode } \\ \text { BECN } & \text { Backward Explicit Congestion Notification } \\ \text { BISDN } & \text { Broadband Integrated Services Digital Network } \\ \text { CAC } & \text { Call Admission Control } \\ \text { CBDS } & \text { Connectionless Broadband Data Services } \\ \text { CBR } & \text { Constant Bit Rate } \\ \text { CCR } & \text { Current Cell Rate } \\ \text { CDMA } & \text { Code Division Multiple Access } \\ \text { CDV } & \text { Cell Delay Variation } \\ \text { CDVT } & \text { Cell Delay Variance Tolerance } \\ \text { CER } & \text { Cell Error Ratio } \\ \text { CI } & \text { Congestion Indication } \\ \text { CLR } & \text { Cell Loss Ratio } \\ \text { CMR } & \text { Cell Misinsertion Ratio } \\ \text { CPODA } & \text { Contention based Priority Oriented Demand Assignment } \\ \text { CS } & \text { Convergence Sublayer } \\ \text { DAMA } & \text { Demand Assignment Multiple Access } \\ \text { DES } & \text { Destination End System } \\ \text { DLC } & \text { Data Link Control } \\ \text { DPF } & \text { Down Pressure Factor } \\ \text { EFCI } & \text { Explicit Forward Congestion Indication } \\ \text { EPRCA } & \text { Enhanced Proportional Rate Control Algorithm } \\ \text { ER } & \text { Explicit Rate } \\ \text { Explicit Rate Indication for Congestion Avoidance }\end{array}$


FDMA Frequency Division Multiple Access

FRM Forward Resource Management cell

GEO Geostationary Earth Orbits

HEC Header Error Control

HEO Highly Elliptical Orbits

LEO Low Earth Orbits

MBS Maximum Burst Size

MACR Mean Allowed Cell Rate

MCR Minimum Cell Rate

MEO Medium Earth Orbits

NE Network Element

NI No Increase

Nrm Number of Cells between FRM Cells

nrt-VBR Non-real Time Variable Bit Rate

OAM Operation and Maintenance

OPNET Optimised Network Engineering Tools

PCR Peak Cell Rate

PDU Protocol Data Unit

PHY Physical Layer

PN Pseudo Noise

PRCA Proportional Rate Control Algorithm

QL Queue Length

QoS Quality of Service

RIF Rate Increase Factor

RDF Rate Decrease Factor

RM Resource Management

rt-VBR Real Time Variable Bit Rate

SAP Service Access Point

SAR Segmentation and Reassembly

SCR Sustainable Cell Rate

SDU Service Data Unit 
SECBNR Severely Errored Cell Block Ratio

SES Source End System

SMDS Switched Multi-megabit Data Services

SN Sequence Number

TDMA Time Division Multiple Access

Trm Time between FRM Cells

UBR Unspecified Bit Rate

UNI User-to-Network Interface

UPC Usage Parameter Control

VBR Variable Bit Rate

VCI Virtual Channel Identifier

VD Virtual Destination

VPI Virtual Path Identifier

VS Virtual Source

WATM Wireless Asynchronous Transfer Mode

WMAC Wireless Medium Access Control 


\section{ACKNOWLEDGEMENTS}

I would like to thank my supervisor Dr. Rahim Tafazolli and Mr. Ioannis Mertzanis for their excellent guidance and thoughtful consideration.

And I appreciate my Korea Government to support me during this course. During this two years, I have had enough time to study and think about my country, my family, and my life as well. I would like to dedicate this work to : my father, my mother, my wife, my son Deok-jin and my daughter Hye-jin.

I also would like to thank all CCSR friends for the great time we had together in this lovely place. 


\section{SUMMARY}

ATM is specified as a standard for multimedia communications, which provides universal information exchange independent of the end system and the types of traffic (data, audio, video). In addition, it is suitable for high speed networks, and provides flexibility and scalability in the network design. Satellite communication systems have also considered ATM as a technology for the global network infrastructure. The role of satellites have changed from purely transparent communication nodes to fast packet switching nodes in the sky.

An ATM on-board satellite switch can be seen as a key network entity for the future global communication systems. It is a promising means to increase the bandwidth efficiency and to provide QoS guarantees. But, because the resources of satellite communication systems are limited and more expensive when compared to those of terrestrial systems, the design of an ATM on-board switch needs careful considerations. The long propagation delay, the maximum utilisation of the network resources and the QoS guarantees of multimedia services are considered as the main design parameters. To meet these requirements, a satellite system should employ a robust congestion control scheme.

In this thesis an investigation of the congestion control schemes suggested by ATM Forum followed by a new proposal are presented. The new scheme was implemented in OPNET modeller and its performance was evaluated through simulation. The work presented here focuses on the performance evaluation under various traffic conditions. 


\section{INTRODUCTION}

Satellite communication systems are now an indispensable part of most major telecommunication systems. They have various capabilities for providing global coverage, point to multi-point and broadcast transmissions, rapid deployment, flexible network re-configuration, bandwidth on-demand and distance insensitive cost. With these advantages, satellite communication systems could meet the users requirements for global, multimedia services. Without satellite communication systems a fast and economical global information infrastructure will not be realised. Recently many new generation satellite communication systems are proposed involving GEO (Geostationary Earth Orbits), MEO (Medium Earth Orbits) and LEO (Low Earth Orbits) constellations using high gain multi-spot-beam antennas and high frequency band operation.

One of the challenging technologies is the ATM (Asynchronous Transfer Mode) onboard satellite switching which has been recognised as a solution for the next generation multimedia systems. The ATM on-board switch offers the integration of voice, video and data services and supports different transmission rates. The on-board signal regeneration and ATM switching increases the complexity of the satellite payload but it also offers many advantages such as high satellite bandwidth utilisation, small ground terminal antenna size and better link quality. In addition, it allows for the optimisation of the access scheme and the improvement of link budget by separating the up link and down link noise contributions [1].

The ATM Forum Traffic Management Specification currently defines five different service classes to support the Quality of Service $(\mathrm{Q} o S)$ requirements of diverse traffic types [2]. These are the Constant Bit Rate (CBR), real-time Variable Bit Rate (rtVBR), non-real time Variable Bit Rate (nrt-VBR), Available Bit Rate (ABR), and Unspecified Bit Rate (UBR). 
The CBR service is aimed at transmitting voice and other synchronous applications, the VBR service is specified to support video and audio applications and the $A B R$ and UBR services are designed to support data. Each service category is defined using a traffic contract which specifies the characteristics of the source traffic and a set of QoS parameters negotiated by the source and the network.

One of the main issues in designing ATM networks is maintaining the balance between guaranteeing performance for each service class and allowing enough statistical sharing of bandwidth so that the network is efficiently utilised. In conventional circuit switched networks, each connection is allocated a fixed amount of bandwidth and a constant transmission rate in the network is provided to communicating nodes throughout the duration of the connection. But, the traffic and congestion control in ATM networks is much more complex due to the aggregated sources and the random nature of the traffic arrival patterns. Therefore, it is necessary to allocate and control the traffic so that the network can operate at acceptable levels even at times when the offered traffic to the network exceeds its capacity. In very high speed ATM networks, once the switch is congested, its buffers will start to overflow and cells will be dropped. As the traffic intensity increases, the switch becomes more congested and eventually the network can reach a catastrophic state.

The main drawback of satellite communication systems is the long propagation delays. These delays have a significant impact on the service quality of satellite networks, especially for the bursty, high speed multimedia services. In addition, the resources of satellite communication systems are limited and expensive compared to those of terrestrial system. Furthermore, satellite communication systems should provide a high level of integration with terrestrial systems. Congestion control for ATM terrestrial systems has been studied extensively, but not for the satellite segment. It is very important that satellite communication systems should employ a robust congestion control mechanism. 


\subsection{OBJECTIVES}

The main objective of this work is to suggest a robust congestion control scheme for ATM on-board satellite switches. In order to achieve this goal, we have specified the following tasks :

- Investigate the conventional congestion control schemes

- Identify the paraneters that have an impact on the QoS of the supported services

- Suggest a new congestion control scheme

- Develop a simulation model and evaluate the performance of the suggested congestion control scheme

\subsection{ORGANIZATION OF THIS THESIS}

The remaining section of this thesis is arranged as follows. In section 2 and 3 , the basic concepts of ATM networks and conventional congestion schemes are reviewed. In section 4, a new congestion control scheme applicable for satellite ATM networks is described and finally, simulation results and conclusions are given in section 5 and 6 respectively. 


\section{REVIEW ATM STRUCTURE AND FUNCTIONS}

\subsection{ATM PROTOCOL STRUCTURE}

In ATM, user and network control information is carried in fixed size packets which are called cells. Each cell is 53 bytes, consisting of 5-bytes header and 48-bytes payload. This format is independent from the service requirements. For high speed cell switching, the virtual circuit concept has been selected for BISDN (Broadband Integrated Services Digital Network) [3]. ATM is a connection oriented transfer mode. In other words, any communication process in a BISDN network is composed of three phases, that is virtual circuit call set up, information transfer, virtual circuit call tear down. ATM utilises the connection oriented technique and the statistical multiplexing technology.

In 1988, ATM was selected by the ITU as a transport mechanism for BISDN networks [4]. The BISDN protocol architecture is shown in Fig. 2-1, 2-2. Three planes are defined : the user plane, the control plane and the management plane. The user plane transfers the information flow through all the layers. The control plane is responsible for setting, releasing and monitoring data connections. The management plane coordinates all procedures and functions such as meta-signalling and OAM (Operation and Maintenance). 


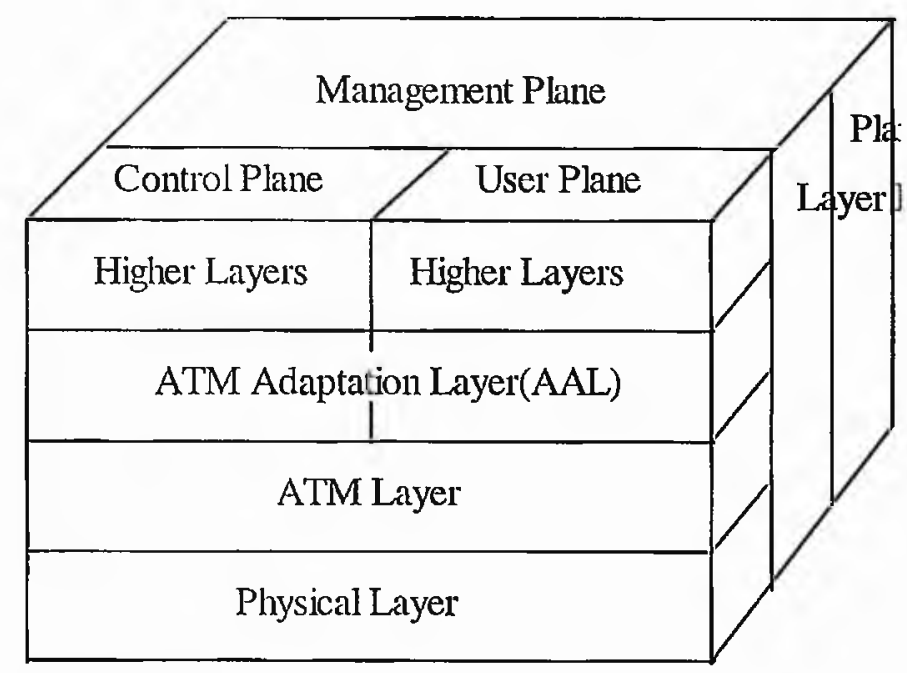

Fig.2-1 Reference Model of BISDN Protocol(from[Othmar Kyas,

"ATM Networks",P.71])

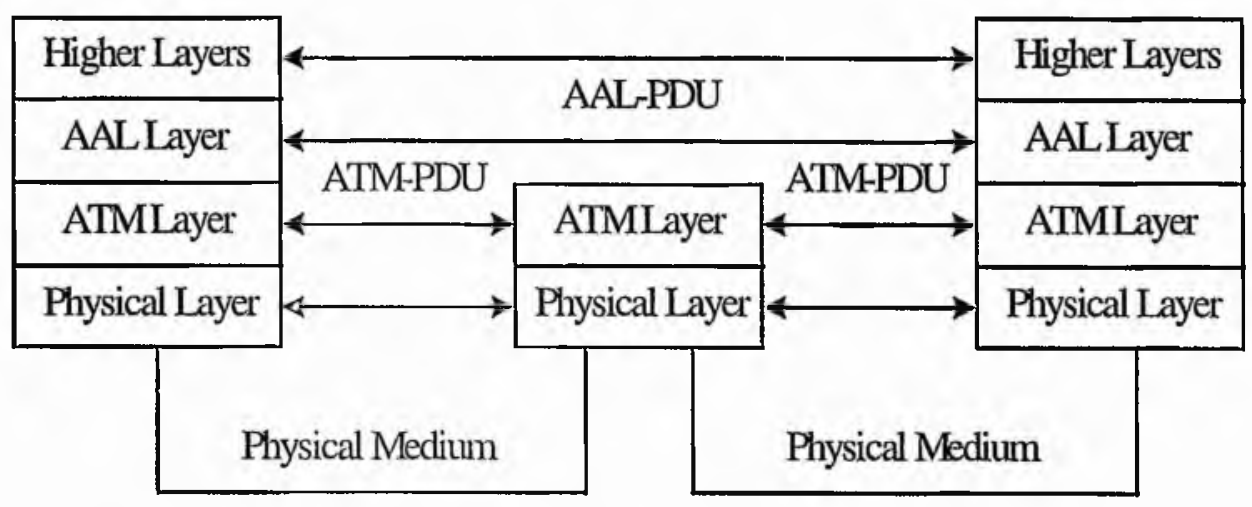

End User

ATMSwitching Node

End User

PDU: Protocol Data Unit

Fig. 2-2 An ATM Network Interface(from[Achille Pattavina, "Switching Theory", P.11]) 


\subsection{FUNCTIONS OF ATM LAYERS}

\subsubsection{THE PHYSICAL LAYER}

The physical layer consists of two sub-layers : the transmission convergence sub-layer and the physical medium. The physical medium provides bit-transmission capabilities, including the generation and reception of waveforms, insertion and extraction of symbol timing. The transmission convergence sublayer performs HEC (Header Error Control) generation and verification, frame and cell delineation, and line coding. On the transmit side, this layer inserts idle cell when no cells are passed from the ATM layer.

\subsubsection{THE ATM LAYER}

The ATM layer receives information units from the AAL layer, and generates the appropriate ATM headers. The size of information units in this layer is 53 bytes including 5 bytes of cell header in which the connection identifier is located. The main functions of this layer are cell multiplexing, de-multiplexing, cell switching using the Virtual Path Identifier (VPI) and the Virtual Channel Identifier (VCI) fields of the cell header. ATM layer also manages cell flows to ensure that connections stay within the limits negotiated at the call set up phase. 


\begin{tabular}{|c|c|c|}
\hline Generic Flow Control & \multicolumn{2}{|c|}{ Virtual Path Identifier } \\
\hline Virtual Path Identifier & \multicolumn{2}{|c|}{ Virtual Channel Identifier } \\
\hline \multicolumn{3}{|c|}{ Virtual Channel Identifier } \\
\hline Virtual Channel Identifier & Payload Type & Cell Loss Priority \\
\hline \multicolumn{3}{|c|}{ Header Error Control } \\
\hline
\end{tabular}

Fig 2-3 Cell Header for User-to-Network Interface(UNI)

(from[Othmar Kyas, "ATM Networks", P.74])

\subsubsection{THE ATM ADAPTATION LAYER(AAL)}

The ATM Adaptation layer supports higher layer functions and connections between ATM and non-ATM interfaces. The main role of this layer is to segment the data streams from the higher layers into 48 byte units and to reassemble the original data stream from ATM cells. Furthermore, it provides the required quality of services to each service connection. As shown Fig. 2-4 [5], a user data unit passes from a higher layer entity to the AAL-SAP (ATM Adaptation Layer-Service Access Point) to be delivered to a given end user application. This data unit, which represents the Service Data Unit (SDU) of the AAL layer (AAL-SDU), is encapsulated within a Protocol Data Unit (PDU) of CS sub-layer of AAL. If the AAL-CS-PDU data unit is larger than 48 bytes, it is segmented into several fixed size units. The AAL-SAR-PDU (48 bytes) is transmitted through the ATM-SAP and becomes the ATM-SDU. The ATM layer adds a header of 5 byles to each ATM-SDU, which is called ATM-PDU that is the ATM cell of 53 bytes. 


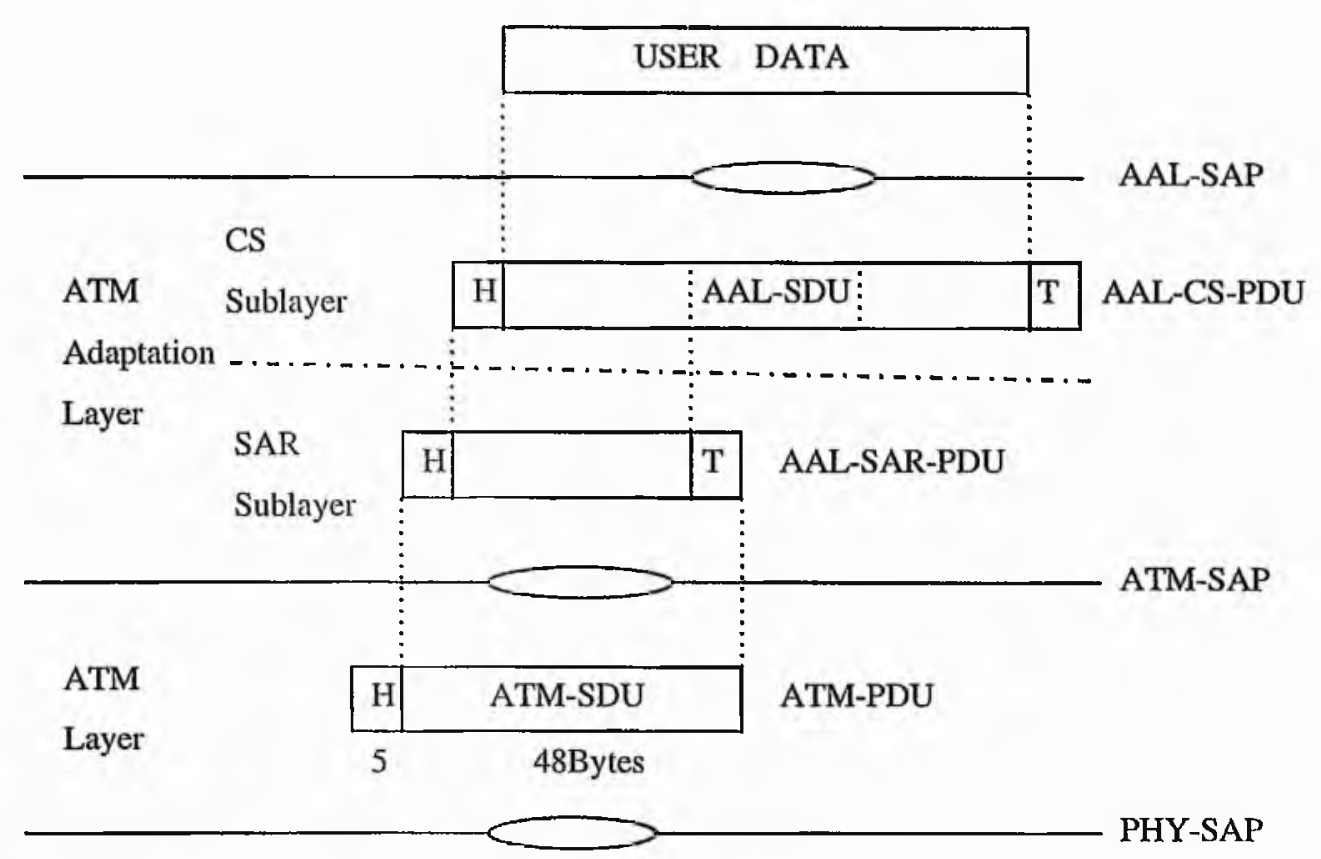

CS Convergence Sublayer

H Header

PDU Protocol Data Unit

PHY Physical Layer

SAP Service Access Point

SAR Segmentation and Reassembly

$\mathrm{T}$ Trailer

Fig. 2-4 Data Units in ATM Protocol(from[Achille Pattavina, "Switching Theory", P.38J)

\subsubsection{THE HIGHER LAYERS}

Higher Layers are the initial applications for BISDN which include cell relay, frame relay, SMDS (Switched Multi-megabit Data Service) / CBDS (Connectionless 
Broadband Data Services), BISDN signalling, LAN emulation, and various video services.

\subsection{ATM SERVICES CATEGORIES}

The basic service concept provided by ATM networks is end to end sequential cell transport. The service is initiated by a user request for a virtual connection, which is either admitted or rejected by the network in terms of the level of connection admission control. After a connection is accepted, the transmitted cells may suffer two types of impairments within the network : delay and loss.

The service class associated with a given ATM connection is indicated to the network at the call set up time and will not change for the duration of that ATM connection. A specified QoS class defines a set of performance parameters and the objective values for each performance parameter should be identified.

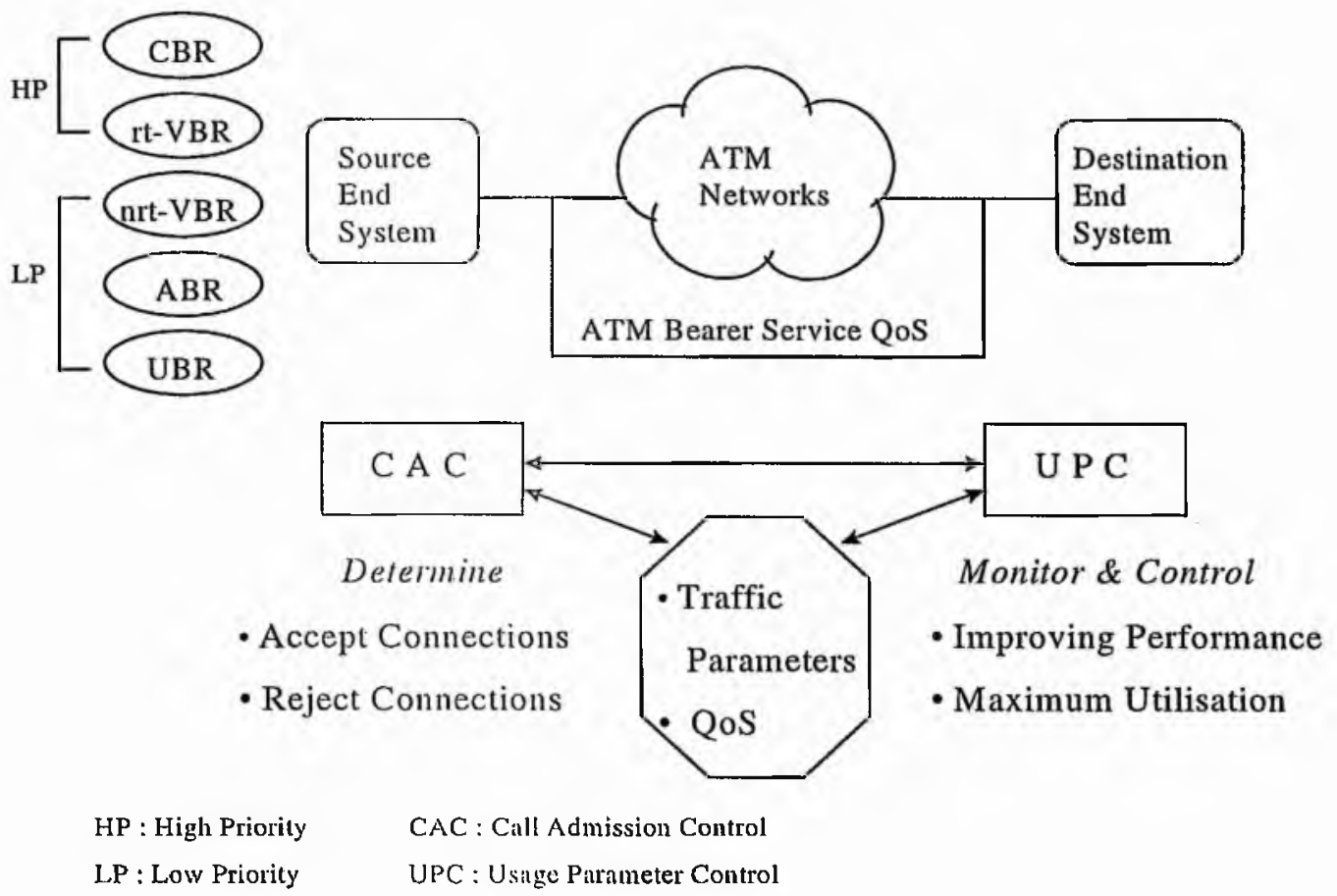

Fig. 2-5 ATM Network and Its service Categories 
Five ATM service categories are defined by the ATM Forum : CBR, rt-VBR, nrtVBR, UBR, ABR. These service categories relate traffic characteristics and QoS requirements to network behaviour as shown in Fig. 2-5. CBR and rt-VBR service categories support real time traffic, whereas all other services support non real time traffic.

\section{- CBR service category}

This category is used by connections that request a static amount of bandwidth that is continuously available during the connection lifetime. This bandwidth is characterised by a PCR (Peak Cell Rate) value. CBR service is intended to provide real time applications requiring tightly constrained delay variation such as voice, video, circuit emulation.

\section{- Real time VBR service category}

The real time VBR service category is intended for real time voice and video applications that requiring tightly constrained delay and delay variation.

This service category connections are characterised by PCR, SCR

(Sustainable Cell Rate), and MBS (Maximum Burst Size). Real time VBR sources are described as bursty which vary their rate with time.

\section{- Non real time VBR service category}

The non real time VBR service category is used to support bursty characteristic traffics which are specified by PCR, SCR and MBS. Bandwidth for this service is allocated statistically to achieve a large link utilisation.

Usually, according to the sensitivity of CDV (Cell Delay Variation), applications are divided into rt-VBR and nit-VBR. An example of rt-VBR service category is interactive compressed video and that of nrt-VBR is video on-demand.

\section{- ABR service category}

$A B R$ is defined for which the limiting ATM layer transfer characteristics provided by the network may change subsequent to connection establishment. 
$A B R$ service is not intend to real time applications. At the call set up stage, the $A B R$ source may be designated as peak cell rate and minimum cell rate by the network. The flow and congestion control mechanism with ABR service is proposed recently, which supports several types of feedback to control the source rate in response to changing ATM layer transfer characteristics.

\section{- UBR service category}

This service category is intended for non real time applications willing to use the bandwidth left available by all the other classes without any objective on CLR and CTD. But, the network may determine a set of internal objectives for the performance parameters. Examples of such applications are traditional computer communication applications such as file transfer and E-mail. If the network is congested, the cells of this category are discarded first. As a result, this service category is called as the best effort service category.

\subsection{QoS AND TRAFFIC PARAMETERS}

\subsubsection{QUALITY OF SERVICE PARAMETERS}

When ATM cells from various service classes are multiplexed, they may be delayed because cells from another class are inserted at the multiplexer. Furthermore, ATM cells are also delayed due to the physical layer processing or the OAM cell transmission. CAC (Connection Admission Control) and UPC (Usage Parameter Control) are fundamental parts of ATM networks. The switched VPCs and VCCs are negotiated, established, modified, and terminated by means of CAC and UPC control.

The delay Parameters consist of CTD (Cell Transfer Delay) and CDV (Cell Delay Variation). The CTD is defined as the elapsed time between measurement points, 
which includes fixed delay by transmission system and the CDV by buffering and cell scheduling.

\section{Negotiated QoS parameters}

- Peak-to-peak CDV (Peak to Peak Cell Delay Variation)

- Max CTD (Maximum Cell Transfer Delay)

- CLR (Cell Loss Ratio) $=\frac{\text { Lost cells }}{\text { Total transmitted cells }}$

\section{Not negotiated QoS parameters}

- CER (Cell Error Ratio)

- SECBR (Severely Errored Cell Block Ratio)

- CMR (Cell Misinsertion Ratio)

\subsubsection{TRAFFIC PARAMETERS}

A traffic contract is determined by the traffic description of the connection characteristics. The traffic description can be divided into source traffic description and connection traffic description.

\section{Source traffic description}

- PCR (Peak Cell Rate)

- SCR (Sustainable Cell Rate)

- MBS (Maximum Burst Size)

- MCR (Minimum Cell Rate)

\section{Connection traffic description}

- Source traffic descriptor 
- CDVT (Cell Delay Variation Tolerance)

- Conformance definition

\begin{tabular}{|c|c|c|c|c|c|c|c|}
\hline \multirow[b]{2}{*}{ Attributes } & \multicolumn{3}{|c|}{ Traffic Pramelers } & \multicolumn{3}{|c|}{ QoS Parameters } & \multirow{2}{*}{$\begin{array}{c}\text { Others } \\
\text { Feedback }\end{array}$} \\
\hline & $\begin{array}{l}\text { PCR } \\
\text { CDVT }\end{array}$ & $\begin{array}{l}\text { SCR, } \\
\text { MBS, } \\
\text { CDVT }\end{array}$ & MCR & $\begin{array}{l}\text { pk-to-pk } \\
\text { CDV }\end{array}$ & $\operatorname{maxCTD}$ & CLR & \\
\hline CBR & 0 & $\mathrm{X}$ & $X$ & 0 & 0 & 0 & $\mathrm{X}$ \\
\hline rt-VBR & 0 & 0 & $\mathrm{X}$ & 0 & 0 & 0 & $\mathrm{X}$ \\
\hline nrt-VBR & 0 & 0 & $\mathrm{X}$ & $X$ & $\mathrm{X}$ & 0 & $\mathrm{X}$ \\
\hline UBR & 0 & $X$ & $X$ & $\mathrm{X}$ & $\mathrm{X}$ & $\mathrm{X}$ & $X$ \\
\hline $\mathrm{ABR}$ & 0 & $\mathrm{X}$ & 0 & $X$ & $X$ & * & 0 \\
\hline
\end{tabular}

$$
\begin{aligned}
0 & : \text { Specified } \\
\mathrm{X} & : \text { Unspccificd } \\
* & : \text { A low CLR }
\end{aligned}
$$

Table 2-1 ATM Attributes for Service Categories

\subsubsection{PEAK CELL RATE (PCR) CONFORMANCE}

PCR is the maximum rate at which cell can be transmitted across a virtual circuit, specified in cells per second and defined by the interval between the transmission of the last bit of one cell and the first bit of the next. 
CDV or CDVT measures the allowable variance in delay between one cell and the next, expressed in fractions of a second. When emulating a circuit, CDV measurements allow the network to determine if the cells are arriving too fast or too slow.

As shown in Fig. 2-6, after being multiplexed at the multiplexer, the traffic sources are conformed with peak emission by the virtual shaper which carries out smoothness of the cell flows. One or more private network elements contribute to CDV. The CDVT is defined in relation to the PCR according to the GCRA(Generic Cell Rate Algorithm). In PCR for the ATM connection, GCRA(T,CDVT) is defined at the public UNI(user network interface), GCRA(T, CDVT*) is defined at the private UNI.

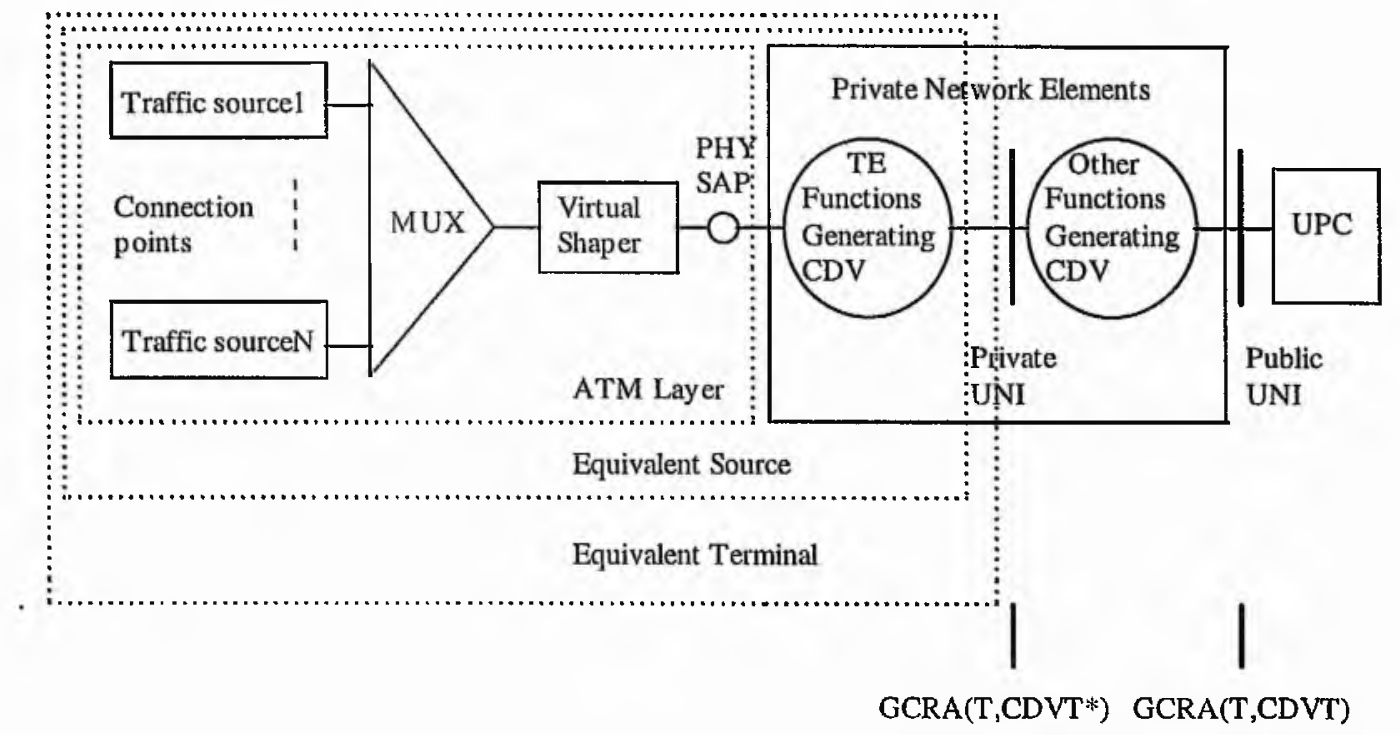

CDVT* $^{*}$ Cell Delay Variation Tolcrance measured at the private UNI.

Fig. 2-6 PCR Reference Model(from [ATM Forum, "Traffic Management Specification V. 4.0",4 1996, p25. 


\subsubsection{SUSTAINABLE CELL RATE(SCR) CONFORMANCE}

The SCR is an upper bound on the average rate of the conforming ATM cells in order to achieve maximum throughput bursty traffic without risking cell loss. With reference to the sustained emission interval Ts (inverse of the SCR), SCR and BT (burst tolerance) parameters can apply to rt-VBR, nrt-VBR services. The CDVT at the UNI is defined in relation to the SCR according to the algorithm GCRA (Ts , $\mathrm{BT}+\mathrm{CDVT}$ ) as shown in Fig. 2-7.

For VBR traffic, MBS(Maximum Burst Size) and BT(Burst Tolerance) are employed. These parameters are provided by the user during the connection establishment stage. The MBS in number of cells is given by

$$
\mathrm{MBS}=1+\frac{T_{s}-T}{B T}
$$

In the signalling message, the BT is conveyed through the MBS which is coded as a number of cells. If an end system chooses a specific SCR and BT traffic parameters and wants to transmit conforming bursts at the peak rate, then the appropriate choice of Ts and BT depends on the minimum spacing between bursts as well as burst size. BT is calculated as

$$
\mathrm{BT}=(\mathrm{MBS}-1) /(1 / \mathrm{SCR}-1 / \mathrm{PCR})
$$




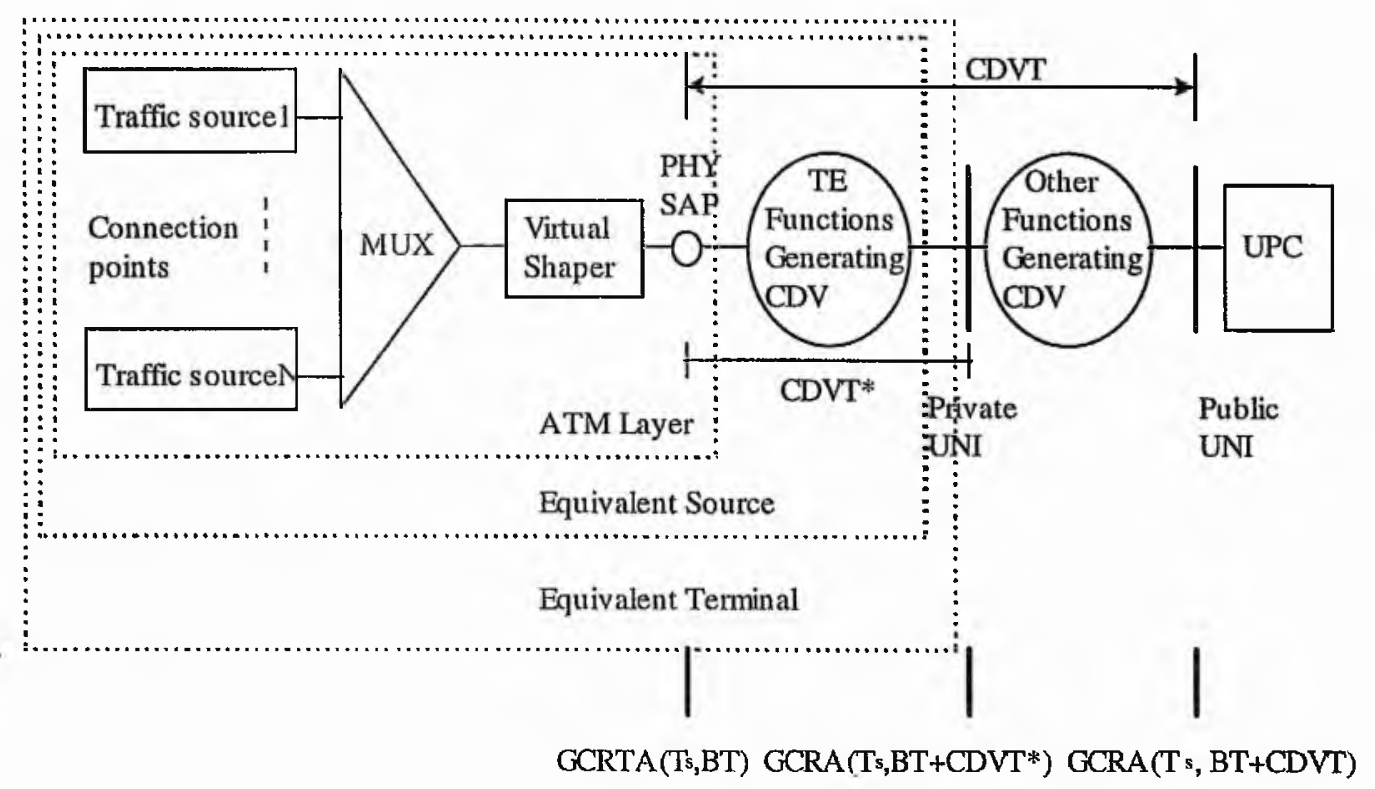

Fig. 2-7 SCR Reference Model(from [ATM Forum,

"Traffic Management Specification V. 4.0",4 1996, p26. 


\section{CONGESTION CONTROL IN ATM} NETWORKS

\subsection{INTRODUCTION}

A key issue in ATM network design is the resource management, i.e., how to make the best use of the available resources. Traffic management includes traffic policing, scheduling, admission control and traffic contract negotiation. An ATM network is in congestion condition if it is no longer able to support the agreed performance parameters for an existing comnection. Congestion can be caused by :

- Unpredictable statistical fluctuations in the traffic flows.

- Errors within the network.

ATM Forum documentation states that a prinary role of traffic management is to protect the network and the end system from congestion in order to achieve network performance objectives and functions of congestion control are intended to react to network congestion in order to minimise its intensity, spread and duration. To meet the QoS requirements of different ATM service classes, ATM networks can implement one or a combination of following functions.

- CAC is defined as the set of actions taken by the network during call set-up phase to determine whether a connection request can be accepted or rejected.

- Feedback controls are defined as the set of actions taken by the network and by the end systems to regulate (he traffic submitted on ATM connections according to the 
state of network elements.

- UPC is defined as the set of actions taken by the network to monitor and control traffic, in terms of traffic offered and validity of the ATM connection, at the end system access.

Its main purpose is to protect network resources from malicious as well as unintentional misbehaviour, which can affect the QoS of other already established connections, by detecting violations of negotiated parameters and taking appropriate actions. Such actions may include cell discard and cell tagging.

- Cell loss priority control allows the user to generate different priority traffic flows by using CLP bit. If the network is congested, it may selectively discard cells marked with a low priority, to protect high priority cells.

- Traffic shaping is a mechanism that modifies the traffic characteristics to reserve bandwidths via connection traffic description.

- NRM (Network Resource Management) is used to allocate network resources to the separated connections according to service characteristics. Although cell scheduling and resource provisioning are implemented, they can be utilised to provide appropriate isolation and access to resources. Virtual Paths are a useful tool for resource management.

- Frame discard is a frame level discard mechanism rather than cell level discard.

- ABR flow control protocol may be used to adaptively share the available bandwidth among participating users. 


\subsection{THE ABR TRAFHIC MANAGEMENT}

\subsubsection{ABR FEEDBACK CONTROL}

The ABR service category was developed to ensure that network resources are divided fairly, and efficiently among the competing connections. The real time service categories, CBR and VBR, require more tightly controlled cell loss, cell transfer delay, cell delay variation objectives. To maintain their QoS, they do not change dynamically their rates which are negotiated at the set up time. It is called open-loop control. On the other hand, in the ABR service, the source adapts its rate to the changing network conditions. Information about the state of the network such as bandwidth availability, state of congestion, is conveyed to the source through special cells called RM (Resource Management) cells. So, this ABR feedback scheme is called closed loop control. This feedback is usually based on the amount of buffer space available in the switch.

The feedback mechanism for congestion control can be divided into credit based control and rate based control. In credit based control, the source needs to receive credits, the specific amount of cells for the VC before transmitting any data cell. Each switch performs a continuous control of the traffic in order to guarantee avoidance of cell loss. On the other hand, rate based control assumes that the rate for the VC sharing a link can be made to converge on sensible value. The switch monitors the feedback RM cells and uses it directly in its input policing. The advantages of the rate based proposal which is accepted as an ATM standard by ATM Forum meeting in Ottawa in September 94, is to provide end to end flow control, a wide range of possible implementations characterise by varying degree of cost and complexity [6].

The rate based ABR feedback control also achieves hop-by-hop control in which each switch would send feedback to the previous switch by using VS and VD (Virtual 
Source and Virtual Destination). A virtual source assumes the behaviour of an ABR source end point, so it removes the backward RM cells from the connection.

A virtual destination assumes the behaviour of an ABR destination end point and it turns around the forward RM cells to the virtual sources.

Forward Information Flow

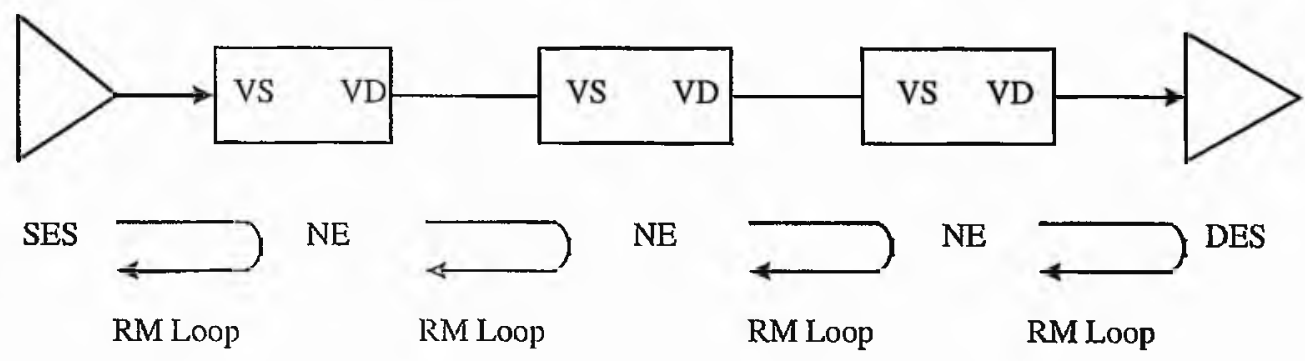

SES : Source End System

NE : Network Element

DES : Destination End System

VS : Virtual Source

VD : Virtual Destination

Fig.3-1 Segmented Feedback Control

\subsubsection{RESOURCE MANAGEMENT CELL}

To obtain network state information, the ABR connection source injects Resource Management (RM) cells into its information cell stream on a regular basis. ABR sources should negotiate several parameters during connection establishment. The first parameter among these is the Peak Cell Rate (PCR) which means the source is allowed to send its cells at the maximum rate. The source can request a Minimum Cell Rate (MCR) which guarantees its minimum cell rate. The rate at which an ABR 
source is allowed to send at the current instant is called the Allowed Cell Rate (ACR). The ACR is dynamically changed between MCR and PCR. The Initial Cell Rate (ICR) is the rate which a source should transmit at the beginning of connection and after an idle period.

All RM cells have the standard header of five bytes with PT $=110$ (binary) for a VCC, and additionally VCI $=110$ for VPC. The CLP bit is 0 if the RM cell is in rate and 1 if it is out of rate in the RM cell format as shown in Table 3-1.

Most RM cells are counted as a part of their network load, which means the total rate of connection including its RM cells should not exceed the ACR of the source. But, the out of rate RM cells are not counted in the ACR of the source. The protocol ID identifies the service using the RM cell. The ITU has assigned protocol ID=1 to ABR service. In message type field, DIR bit indicates the RM cell direction, BN bit indicates whether the RM cell is a BECN (Backward Explicit Congestion Notification) cell or not, CI (Congestion Indication) bit allows to know congestion, NI (No Increase) bit is used to prevent a source from increasing its ACR.

The ER (Explicit Rate) field is usually set to PCR by the source, then may be modified and returned by congested switches along the ABR connection path to the desired value. When the backward RM cell is received by the source, the cell rate value advertised in the ER field defines an explicit upper bound at which the source may transmit its cells to the network. The ER field is two bytes size which expresses binary floating point for its cell rate in cell/sec. The cell rate $\mathrm{R}$ is consisted of the 5 bits exponent(m), the 9 bits mantissa(k), and an additional one bit $\mathrm{nz}$ indicator which allows the ER value to be marked to 0 cells/s or MCR at the call set up if it is necessary [7]. 


\begin{tabular}{|l|c|}
\hline FIELD & B YTES \\
\hline ATM Header & 5 \\
\hline I D & 1 \\
\hline Message type & 1 \\
\hline E R & 2 \\
\hline CCR & 2 \\
\hline MCR & 2 \\
\hline Q L & 4 \\
\hline S N & $30(246)$ \\
\hline Reserved & $2(10)$ \\
\hline CRC - 10 & 4 \\
\hline
\end{tabular}

Message type field

\begin{tabular}{|c|c|c|c|c|c|c|c|}
8 & 7 & 6 & 5 & 4 & 3 & 2 & 1 \\
\hline DIR & BN & CI & NI & RA & RES & RES & RES \\
\hline
\end{tabular}

$$
\begin{aligned}
\text { DIR } & =0 \text { for forward RM cells } \\
& =1 \text { for backward RM cells }
\end{aligned}
$$

$\mathrm{BN}=1$ for non-source generated(BECN) RM cells

$=0$ for source generated RM cells

$\mathrm{CI}=1$ to indicate congestion

$=0$ otherwise

$\mathrm{NI}=1$ to indicate no additive increase allowed

$=0$ otherwise

RA not used for ABR

RES Reservation

( ) : exact number of bit

Table 3-1. Resource Management Cell Format

\begin{tabular}{|l|c|c|c|}
\hline Unused & $n z(1)$ & $m(5)$ & $k(9)$ \\
\hline
\end{tabular}

Table 3-2. $\quad$ Floating Point Bit Position for the Two Bytes RM Cell Rate Fields

$$
\begin{aligned}
& R=2^{m}\left(1+\frac{k}{5 ! 2}\right) \times n z \text { cells/s where } \\
& 0 \leq m \leq 31,0 \leq k \leq 511 \text { and } n z=(0,1) .
\end{aligned}
$$


The QL (Queue Length) and SN (Sequence Number) field are not used for ARR service in ATM Forum.

\subsubsection{SOURCE, DESTINATION AND SWITCH RULES}

ATM Forum TM4.0 specifies 13 items of rules for source (virtual source), 6 items for destination, 5 items for switch (see APPENDIX-A).

The source may always send in rate cells at a rate less than or equal to ACR. The value of ACR never exceed PCR, nor less than MCR.

\section{$M C R \leq$ Source Rate $\leq A C R \leq P C R$}

Before a source sends the first cell after connection set-up, it should set ACR to at most ICR and will send an RM cell continuously every Nrm (Number of cells between FRM cells) user cells transmitted but at least once every Trm (Time between FRM cells:100ms). The source rate is controlled by the return of these cells.

RM cell travels through the switches to the destinations. A switch shall implement at least one of the following methods to control congestion at queuing points.

1) EFCI marking : the switch may set the EFCI state in the data cell headers

2) Relative Rate Marking : the switch may set $\mathrm{CI}=1$ or $\mathrm{NI}=1$ in forward and/or backward RM cells

3) Explicit Rate Marking : The switch may reduce the ER field or forward and /or backward RM cells

4) VS/VD Control : the switch may segment the ABR control loop using a virtual source and destination. 
When the cell arrives at the destination, the destination should change the direction bit in the RM cell and return the RM cell to the source. If the destination is congested and cannot support ER value, it reduces ER to whatever rate it can support or set CI or NI bit just like a switch. Sometimes a destination may be too congested, it is allowed to generate BECN (Backward Explicit Congestion Notification) RM cells.

When the RM cell returns backward, each switch may examine the cell and determine if it can support the ER rate for the VC. If ER is too high, the switch should reduce it.

When the RM cell arrives back to the source, the source should reset its rate ACR based on the ER value in the returned RM cell. If a backward RM cell is received with $\mathrm{CI}=1$, then ACR shall be reduced by at least ACRxRDF (Rate Decrease Factor), unless that reduction would result in a rate below MCR, in which case ACR shall be set to MCR.

If the backward RM cell has both $\mathrm{CI}=0$ and $\mathrm{NI}=0$, then the ACR may be increased by no more than PCRxRIF (Rate Increase Factor). If backward RM cell has NI=1, the ACR should not be increased. According to the combination of NI and CI, the up date ACR values are shown as Table3-3.

\begin{tabular}{|c|c|c|c|}
\hline NI & $\mathrm{CI}$ & & ACR VALUE \\
\hline 0 & 0 & $\mathrm{ACR} \leftarrow$ & $\operatorname{Min}(\mathrm{ER}, \mathrm{ACR}+\mathrm{ACRxRIF})$ \\
\hline 0 & 1 & $\mathrm{ACR} \ll$ & $\operatorname{Min}(\mathrm{ER}, \mathrm{ACR}-\mathrm{ACRxRDF})$ \\
\hline 1 & 0 & $\mathrm{ACR} \leftarrow$ & $\operatorname{Min}(\mathrm{ER}, \mathrm{ACR})$ \\
\hline 1 & 1 & $\mathrm{ACR} \leftarrow$ & $\operatorname{Min}(E R, A C R$ - ACRxRDF) \\
\hline
\end{tabular}

Table 3-3. ACR Up-date Values 


\subsection{CONVENTIONAL CONGESTION CONTROL SCHEMES}

\subsubsection{BINARY FEEDBACK SCHEME}

This scheme essentially uses a single bit feedback. The switches perform end to end rate based traffic control by detecting congestion and providing feedback to the source. In this scheme all VCs share a common FIFO buffer and the queue length is monitored by a predefined threshold $\mathrm{T}$. If the queue length exceeds the congestion threshold $\mathrm{T}$, the cells passing through the buffer are set their congestion indication bit that is EFCI bit=1. If the queue length is below the threshold T, the EFCI bit in the cells is set to 0 . When the feedback RM cells are sent only to decrease the source rate, it is called negative polarity of feedback. Otherwise, it is positive polarity of feedback. If the RM cells are sent to decrease and increase the source rate, it is called bipolar feedback.

Binary feedback scheme has a faimess problem [8]. At the same level of congestion connections, the cells travelling more hops have a higher probability of having their EFCI bits set than the cells have small hops. For example, if $\mathrm{p}$ is the probability of EFCI bit being set on one hop, then the probability of EFCI bit being set after ( $\mathrm{n}$ ) hop will be $1-(1-p)^{n}$. That means the long hop connections have very few opportunities to increase their rate. This is called the "bit-down problem". The solutions of bit-down problem are as follows. First, the buffers of the system are divided for each VC or groups of VCs. Secondly, selective feedback or intelligent marking in which the switch computes current rate of VCs as well as their fair share. If the switch is congested, the switch will set only those VCs whose rates are above this fair share value. The VCs whose rates are bellow the fair share are not affected.

A lot of schemes based on binary feedback have been proposed [6]. Explicit Rate Feedback Schemes are also considered as a kind of binary feedback control scheme. 
Their RM cell also contains two bits control bit such as CI (Congestion Indication) bit, NI (No Increase) bit, etc. We compare these schemes in the following section.

\subsubsection{EPRCA SCHEME}

This scheme was considered as an enhancement to the PRCA (Proportional Rate Control Algorithm) where the source sends RM cells at a rate proportional to its current rate [2] [6] [10]. The sources send an RM cell after every (n) data cells. The RM cells contain desired ER (Explicit Rate), CCR (Current Cell Rate) and CI (Congestion Indication) bit. The sources initialise the ER field to their PCR (Peak Cell Rate) and set CI bit to zero. The switch computes a MACR (Mean Allowed Cell Rate) for all VCs using a running exponential weighted average. MACR is calculated by

$\operatorname{MACR}_{(\text {new })}=(1-\alpha) \mathrm{MACR}_{(\text {old })}+\alpha \mathrm{CCR}$, where $\alpha$ is generally chosen to be $1 / 16$, weights the MACR more than the current CCR.

The destinations monitor the EFCI bits in data cells. If a data cell had EFCI bit set, the destination marks the CI bit in the RM cell. The switches also monitor their load by keeping track of the queue length. If their queue length is more than a certain threshold, they can set Cl bit. When the RM cell returns from the destination with CI bit setting, the switch reduces the rate of all connections with ACR larger than MACR. So, the switch maintains the MACR value. The CI bit setting forces the sources to decrease their rate by

$\mathrm{ACR}_{\text {(new) }}=\mathrm{ACR}_{\text {(old) }}-\mathrm{ACR}_{\text {(old) }} \times \mathrm{RDF}$

where RDF is the reduction factor and typically $1 / 16$. 
If the switches are allowed to increase their rate, they change their rate by an amount of AIR (Allowed Increase Rate) which represents the increase rate and is generally chosen to be $1 / 16$.

$\mathrm{ACR}_{(\text {new })=}=\mathrm{ACR}$ (old) $+\mathrm{ACR}$ (old) $\times \mathrm{AIR}$

and, the fair share is set at a fraction of MACR.

Fair Share $=$ MACR $\times$ DPF

where DPF is down pressure factor, typically $7 / 8$.

The problem of this EPRCA scheme is the exponential averaging technique and unfair share. Sources that start up late get lower throughput than those which start early. Furthermore, the measurements of feedback can vary due to disparities in propagation delay, link speed, congestion conditions, scheduling policies, and other factors [9].

\subsubsection{ERICA SCHEME}

The ERICA (Explicit Rate Indication for Congestion Avoidance) tries to monitor periodically the load on each link by a load factor $\mathrm{z}$. The load factor $\mathrm{z}$ is calculated as the ratio of the measured input rate to the target capacity of the output link. The input rate is measured over a fixed averaging interval and the target rate is set at slightly below the link bandwidth [8].

$$
\text { Load Factor } \mathrm{z}=\frac{\text { Input Rate }}{\text { Target Rate }}
$$

And, fair share is computed as follows 
Fair Share $=\frac{\text { Target Rate }}{\text { Number of Active Sources }}$

CCR is the current cell rate field in the RM cell which contains ACR declared by the source or measured by the switch. In order to achieve VCs level fair share, the system monitors all VCs rates.

$$
\text { VC Share }=\frac{C C R}{z}
$$

Using the combination of these two equations, the system can achieve fairness more efficiently. The explicit rate is computed as follows

$$
\mathrm{ER}=\operatorname{Max}(\text { Fair Share, VC Share) }
$$

Sources are allowed to send at a rate of Fair Share in the first round trip. If the VC Share value is greater than Fair Share, the source is allowed to send at VC Share. This equation provides fairness at every step. This ensures the most current information is used to provide fastest feedback. The measurement interval for explicit rate is greater than RM cell rate and the value should be sent to each VC. There are also a few parameters to be maintained.

ERICA gives at most one feedback to the VC source per averaging interval. This provides the accuracy of measurements of the system. If the averaging interval is more longer, the measurements are more correct, but the feedback interval is slower.

If the measurements are not highly time variable, the ERICA is stable. But for the networks with high variance queue lengths, especially when $z$ is close to 1 , the ERICA may become unstable. ERICA depends on the measurement of metrics the load factor and the number of active $A B R$ sources. If there is a high error in the measurement, and the target utilisation is set to very high, the queue may become overflow and ERICA also may diverge. 


\subsubsection{ERICA $^{+}$SCHEME}

ERICA have some useful factors such as averaging interval which gives better accuracy of measurements, load factor $\mathrm{z}$ and the number of active sources. ERICA ${ }^{+}$ scheme is evolved from ERICA by adding the queue threshold. If the queue is greater than the threshold, ERICA $^{+}$reduces its target utilisation, otherwise ERICA ${ }^{+}$ increases it [10][11][12].

In $\mathrm{ERICA}^{+}$scheme, continuous function of queue length is very important parameter. In successive averaging intervals, ERICA+ algorithm keeps track of the queue behaviour and reflect it in the rate allocations.

Target Rate $=f$ (queue length, link rate, VBR rate)

Secondly, it uses target queue length which represents steady state condition i.e., the link is $100 \%$ utilised. Due to high priority classes of traffics, ABR traffic capacity is changed dynamically. If the high priority classes of traffics are absent for a short time, $\mathrm{ABR}$ traffics should increase their rates very quickly and it is possible by continuously monitoring the target queue length.

Thirdly, all queue lengths are measured in time unit rather than cells. And the queue delay T0 is introduced as a new parameter instead of the target utilisation parameter. When the queuing delay drops below the T0, ERICA ${ }^{+}$increases the VC's rate until its queuing delay reaches the TO. When the queuing delay is over the T0, the rate of $\mathrm{VC}$ is reduced. The queue control function uses a queue delay time as a threshold value. This value T0 translates into a queue length as follows,

$$
\mathrm{Q} 0=\text { Total ABR capacity } \times \mathrm{TO}
$$


In $\mathrm{ERICA}^{+}$scheme, the ABR capacity is measured by a given link capacity rather than the link utilisation as in ERICA.

Total ABR capacity = Link capacity - VBR capacity

The target ABR capacity is a fraction of the total ABR capacity and this fraction is a function of the queuing delay $\mathrm{Tq}$ at the switch.

Target ABR capacity $\leftarrow f(\mathrm{Tq}) \times$ Total ABR capacity

Raj Jain [11] suggested the queue control function $f(\mathrm{Tq})$ as below,

$$
f(\mathrm{Tq})=\frac{a \times Q_{0}}{(a-1) \times q+Q_{\|}} \quad \text { for } \mathrm{q}>\mathrm{Q} 0
$$

and

$$
f(\mathrm{Tq})=\frac{b \times Q_{11}}{(b-1) \times q+Q_{0}} \quad \text { for } 0 \leq \mathrm{q} \leq \mathrm{Q} 0
$$

This $f(\mathrm{Tq})$ function has a lower bound with the queue drain limit factor(QDLF),

$$
f(\mathrm{Tq})=\operatorname{Max}\left(\mathrm{QDLF}, \frac{a \times Q_{0}}{(a-1) \times q+Q_{0}}\right) \text { for } \mathrm{q}>\mathrm{Q} 0
$$

The parameter ' $b$ ' determines how much excess capacity would be allocated when the queuing delay is zero and ' $a$ ' determines how quickly the function $f(\mathrm{Tq})$ drops as a function of queuing delay. The range of function $f(\mathrm{Tq})$ is [QDLF, b]. Raj Jain also claims that when the parameter ' $a$ ' and ' $b$ ' have the values 1.15 and 1.05 respectively, the algorithm works well.

In ERICA $^{+}$scheme the queuing length values calculated from queuing delay is a core control parameter as a threshold. But, as queuing delay is a highly variant quantity, a 
small variance in queuing delay may cause large variance in source rates, and it leads to system instability.

Furthermore the desired steady state value $\mathrm{Q} 0$ is also time variable according to source characteristics and $\mathrm{ERICA}^{+}$has not sufficient consideration for the long propagation delay system.

\subsection{SUMMARY AND CONCLUSION}

In this section, the congestion control framework in ATM network and some congestion control schemes suggested by ATM Forum are introduced.

From the ATM switch design point of view, the ATM Forum has provided the manufacturers the freedom to adapt the congestion control scheme for different system applications. In fact, number of congestion control schemes have been proposed since the congestion control framework was specified. The algorithms are mainly based on different variations of the Binary Feedback scheme, the EPRCA and the ERICA which have been discussed thoroughly in ATM Forum.

Unfortunately, both the EPRCA and the ERICA schemes have no functions to lessen the effect of a long propagation delay. In a long propagation delay system, the feedback information which is sent from the switch or the destination to the source suffers from the latency. Especially, in high speed ATM networks, the sources are capable of sending too many cells into the network before the feedback information is received. This mismatch leads to a network congestion.

Another important point is that the management of the switch queue length should be very precisely and tightly. 
In order to achieve a global, broadband multimedia system via satellites, a new congestion control scheme which has resilience to propagation delay characteristic is essential. 


\section{CONGESTION CONTROL FOR ON-BOARD ATM SWHTCHIN INATELLITE SYSTEMS}

\subsection{SATELLITE ACCESS SCHEMES}

\subsubsection{WIRELESS ATM PRO'TOCOL}

The future multimedia satellite systems using advanced technologies foresee the use of Ka-band frequency, multi-beam antennas, on-demand assignment of satellite resources, inter satellite links and on-board baseband signal regeneration ATM switches. Due to these new technologies, satellite communication systems can provide multimedia services to the end users with small size and low cost terminals [13].

The ATM Forum recently formed a wireless ATM working group to make recommendations on wireless ATM issues including satellite networks. There are significant challenges for employing ATM in a satellite link. ATM was essentially designed for high bandwidth, highly reliable optical networks, but the satellite link is inherently unreliable and time varying bandwidth limited. Since the satellite bandwidth is a limited resource, a flexible and efficient bandwidth management scheme is required. Also, an effective error correction coding scheme should be employed in the satellite up and down links because satellite networks are affected by propagation media which can cause multiple bit error rates. Another great challenge is the rate mismatch between wired and wireless media which imposes significant complexity in inter-networking. 
There are other terrestrial wireless ATM standardisation activities : the IEEE standard (802.11), the ETSI's HIPERLAN and the ATM Forum's standard (WATM) [14]. The IEEE 802.11 completed in 1990 defined a framework to incorporate wireless specific issues such as power control, frequency management roaming, and authentication in a LAN standard. HIPERLAN standard was developed in 1992 as European standard for high speed wireless local networks. It defines a priority scheme and QoS control as well as routing, encryption and power conservation. WATM is aiming to develop specifications for radio access, MAC layer, and mobility by the end of 1999. Several proposals have been submitted for consideration including three prototypes which were suggested by Lucent, NEC, and EU Magic WAND project [14].

One of the main key system issues is the development of the appropriate WMAC (Wireless Medium Access Control) protocol which should be able to support seamless wired and wireless networking. These WMAC protocols should be designed to support ATM service classes and their quality of services, to further extend the statistical multiplexing by incorporating the ATM standard protocols.

\subsubsection{MULTIPLE ACCESS SCHEMES}

Multiple access schemes are classified according to the bandwidth allocation mechanism. In general, there are three main categories : fixed assignment, random assignment and on-demand assignment [15].

Fixed assignment techniques reserve one constant capacity channel to each connection during its whole connection. An earth station or a terminal can receive a traffic request from the network, greater than the capacity which is allocated to it. It must then refuse some calls. Fixed access schemes perform well with constant bit rate. But for multiple connections, their performance is dramatically decreased. These techniques are based on FDMA (Frequency Division Multiple Access), TDMA (Time Division Multiple Access), CDMA (Code Division Multiple Access). If the spectra of the carriers 
occupy a different sub-band, the receiver can discriminate between carriers by filtering (FDMA). Several carriers received sequentially at the receiver can be discriminated by the temporal location of carrier energies (TDMA). If the carrier is specified by its special signature which is made of PN (Pseudo Noise) codes, even when all the carries occupy the same frequency band simultaneously, this scheme is called CDMA.

Random access techniques are well suited to networks containing a large number of stations where each station is required to transmit bursty messages. The principle of random access is to allow each station to transmit messages almost without restriction in the form of limited duration bursts which occupy all the bandwidth of the transmission channel. The possibility of collisions between bursts at the satellite switch is accepted. In the case of collision, the transmitting station retransmits the message after some random delay. If an acknowledgement is not received within a fixed time interval which is set to a value slightly greater than twice the round trip propagation time, retransmission will occur. These types of techniques are ALOHA, Selective Reject ALOHA, Slotted ALOHA, etc. [16]. ALOHA types of protocols are easy to implement but they suffer from long delays and instability under heavy traffic loads.

Protocols with on-demand assignment are intended to increase transmission throughput by utilising of a reservation procedure which is called DAMA (Demand Assignment Multiple Access). Users are required to provide explicit or implicit information regarding their needs for bandwidth which will be assigned on-demand. Whenever a user enters an idle period, the assigned bandwidths will be allocated to another user. Unlike other schemes, on-demand assignment schemes minimise wasted bandwidth and perform well under a wide range of bad conditions whilst they are usually more complex to implement. These types of protocols are R-ALOHA, RTDMA and CPODA (Contention based Priority Oriented Demand Assignment) [16].

There are a large number of solutions to choose multiple access schemes. It depends on economic considerations, traffic characteristics and network environments. For 
example, FDMA, TDMA. and CDMA access techniques are most suitable for telephone traffic, television transmission and video conferencing whose traffic characterised by long and continuous messages. Several types of multiple access schemes can also be combined. Most WMAC protocols use DAMA with FD-TDMA schemes due to their abilitics which are dynamic allocation of satellite power and bandwidth, flexible accommodation of connection rates and few time slots depending on current traffic conditions [17] [18]. A example of WMAC frame format is given in Fig. 4-1.

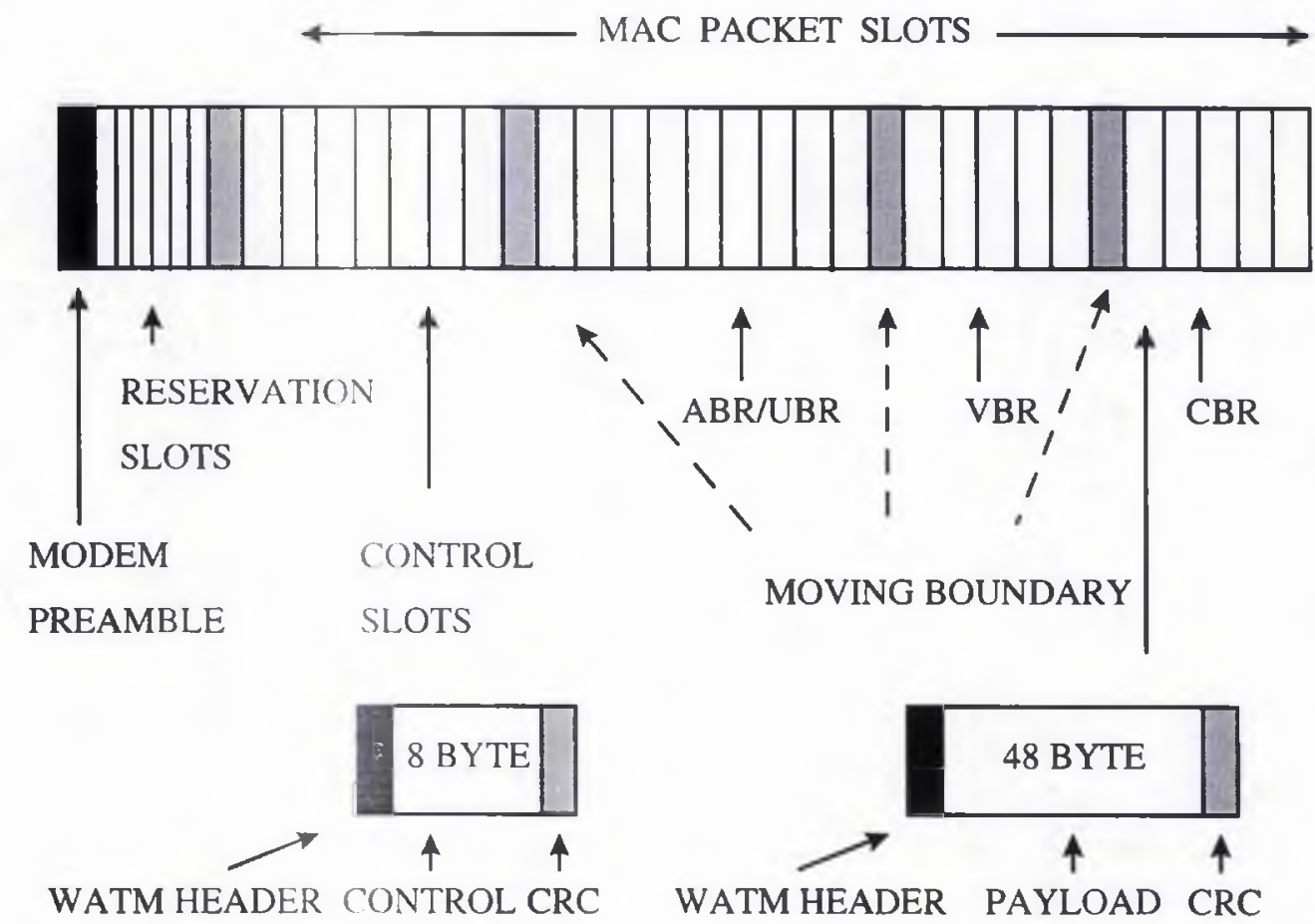

Fig.4-I

Dynamic TDMA WMAC Frame Format 


\subsubsection{WMAC PROTOCOL ARCHITECTURES}

The WMAC protocol using dynamic TDMATTDD channel multiplexing format is shown in Fig.4-2. The protocol architecture consists of a WMAC, a DLC (Data Link Control) wireless physical layer and wireless control layer based on standard ATM Protocol [19]. The WMAC protocol plays a central role to multiplex different classes of traffics over the air interface.

The WMAC protocol hass to be designed considering the following points.

- Maximum gain of multiplexing and utilisation of network resources.

- Minimum transmission frame overhead.

- Minimum cell loss ratio.

- Powerful error recovery functions.

- Guarantee the QoS requirement for all service classes.

- Guarantee the mobility and hand over.

\begin{tabular}{|c|c|c|}
\hline User Process & $\begin{array}{c}\text { ATM Control } \\
\text { Signaling, Q2931,etc. }\end{array}$ & Wireless Control \\
\hline \multicolumn{2}{|c|}{ ATM Adaptation Layer(AAL) } & $\begin{array}{l}\text { Wireless Data } \\
\text { Link Control }\end{array}$ \\
\hline ATM Laye & & Wireless MAC \\
\hline \multirow{2}{*}{ Physical Layer } & \multirow{2}{*}{$\begin{array}{l}\text { Wireless Access } \\
\text { Layer }\end{array}$} & \\
\hline & & $\begin{array}{l}\text { Wireless Physical } \\
\text { Layer }\end{array}$ \\
\hline
\end{tabular}

Fig.4-2 WATM Protocol Architecture 


\subsection{SATELLITE-ATM SYSTEM MODEL ANALYSIS}

\subsubsection{SATELLITE FEEDBACK CONTROL SCHEME}

Congestion control for terrestrial networks has been extensively studied, but most of the schemes are not suilable for the satellite systems due to the different physical layer transmissions characteristics (ie. wireless link and propagation delay).

In general, there are two categories in congestion control for the ATM networks depending on the existence of a feedback control mechanism. These are the preventive congestion control and the reactive congestion control schemes. The preventive congestion control scheme takes an appropriate action before the network is congested, whilst the reactive congestion control scheme removes the causes of congestion after the network is congested.

The preventive congestion control is often called "open loop control", and it tries to maintain the traffic in a non-congested state by shaping it at the source nodes and tries to decide whether to accept or reject a new connection at the call set up time. The preventive congestion control is normally performed by the combination of admission and bandwidth enforcement. On the other hand, the reactive congestion control is "closed loop control", in which the source node traffic is regulated by the destination node or network. In reactive congestion control scheme, the network is monitored and controlled. The source node regulates its traffics continuously according to feedback information from the destination node or network. When congestion is detected, the source traffic should be adjusted to slow down or stop transmission for a while until the congestion is cleared. The main problem of the reactive congestion control scheme is a large propagation delay of control signals. 
In a high speed networks with various traffic types and long propagation delays, the preventive congestion control alone is understood not to be enough. A specific congestion control scheme for satellite networks is needed. Satellite networks should employ both preventive and reactive congestion control schemes. It means that open loop congestion control scheme can be used for real time traffic such as CBR and VBR, while reactive congestion control scheme can be applied for non real time traffic $\mathrm{ABR}, \mathrm{VBR}$, etc. In this work we particularly focus on reactive congestion control scheme which has a robustness to the long propagation delay.

<GROUND STATIONS>

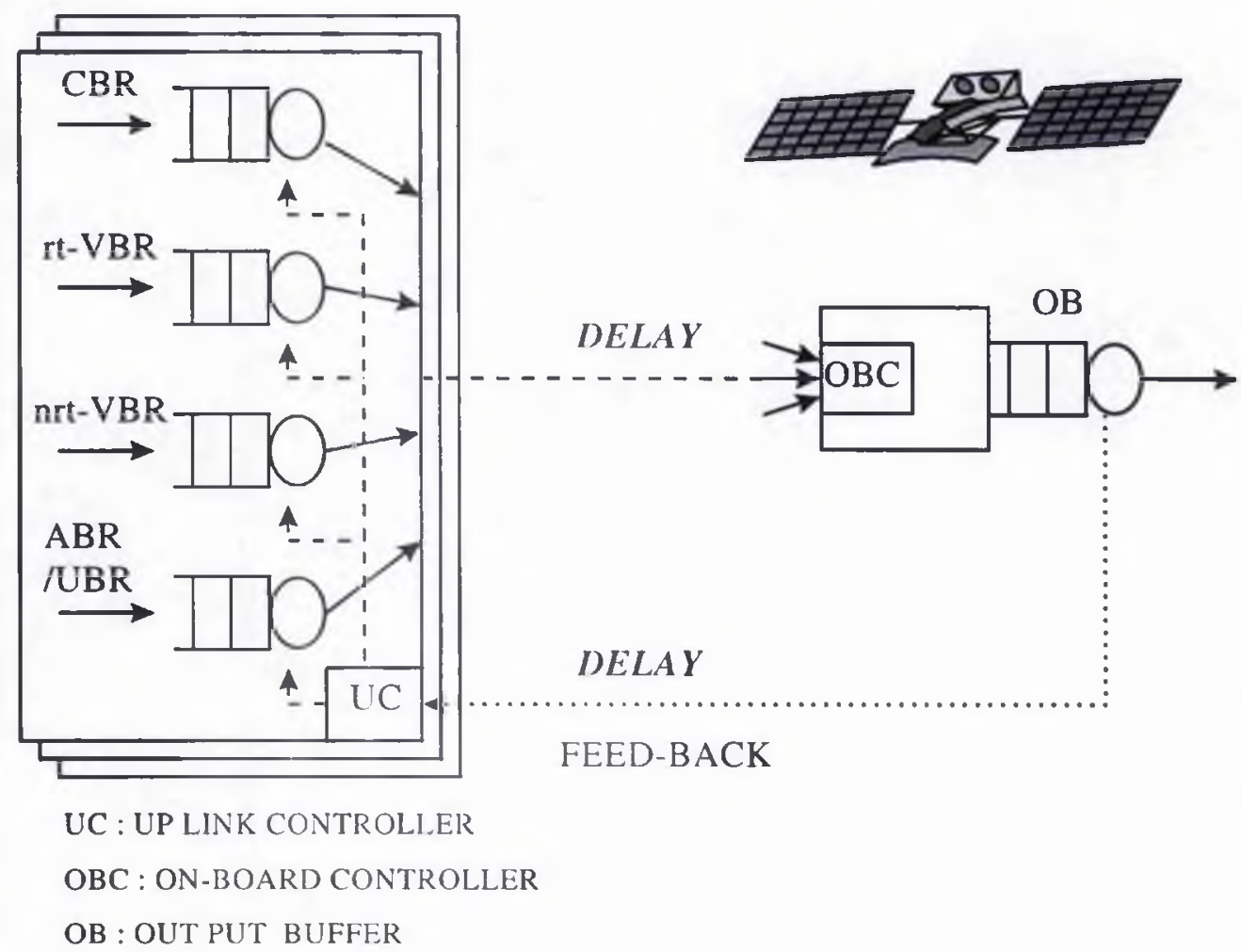

Fig. 4-3 A Simple Satellite System Model

Now we consider a simple satellite network as shown in Fig. 4-3. An on-board switch is expected to provide a statistical multiplexing gain with CBR, VBR and ABR 
sources. It is assumed that a dynamic resource allocation scheme with WMAC and leaky bucket algorithm is used to achieve an efficient utilisation of the system. Traffic controllers in the WMAC play an important role such as shaping and traffic scheduling. It is also assumed thet satellite networks employ all the techniques in the terrestrial networks, such as virtual path and virtual connection, hop by hop control, early packet discard, etc.

The ground stations transmit aggregated traffic streams to the on-board switch. But due to the propagation delay, traffic arrives at the queue after a time delay $\mathrm{Td}$. Every control time period the on-board switch computes each VC queue length, ER value and feed it back to the ground stations. This feedback control information is also delayed by $\mathrm{Td}$, so the ground stations will adjust their rates to the explicit rates after $\mathrm{t}+\mathrm{Td}$. At that time the queue length of the on-board switch may have changed. This mismatch leads to buffer fluctuation and overflow [20]. In other words, the ground stations do not know the exact queue length of the on board satellite switch, ie., they are "queue length blind", because only on board satellite switch can calculate its queue size.

In order to prevent this mismatch, we suggest that a new congestion control scheme in which the on-board satellite switch should calculate its queue length precisely based on current average number of active sources and mean arrival rates and determine the desired input rates and broadcast them to the ground stations periodically. Apparently, this new scheme should provide seamless internetworking with conventional terrestrial networks. 


\subsubsection{TRAFFIC MODEL}

To study an on-board satellite switch at certain rules of buffer size and cell loss probability, the analysis of sources behaviour using a traffic model is very important. Various approaches have been proposed to analyse the statistical behaviour of the multimedia traffic through ATM switch. MMPP (Markov Modulated Poisson Process) and MMBP (Markov Modulated Bernoulli Process) have been widely used for BISDN network models [21]. The difference between MMPP and MMBP is the probability of inter-arrival times. A Poisson process assumes traffics have a negative exponential distributed intel-arrival times, where a Bernoulli process forms geometric(discrete) distributed [22].

MMFF (Markov Modulated Fluid Flow) model is one of the MMPP which gives good solutions in analysing multiplexed bursty traffic. Stochastic fluid flow model was first introduced by Anick el.al. [23]. This model has been used to evaluate the performance of loss priority systems and multi-level threshold buffer management systems $[24][25][26][27]$.

In this work we try to analyse on-off multimedia traffic sources using MMFF model [28]. Fig.4-4 shows the traffic model with $N$ sources. The up link may use FDMA, TDMA, CDMA, FD-TDMA or FD-CDMA techniques and the down link may use TDM. We assume that eath stations are interconnected via output buffer of an onboard satellite switch and congestion occurs at the up link node. In order to concentrate on propagation delay firstly, we also assume that the traffic sources are homogeneous. 


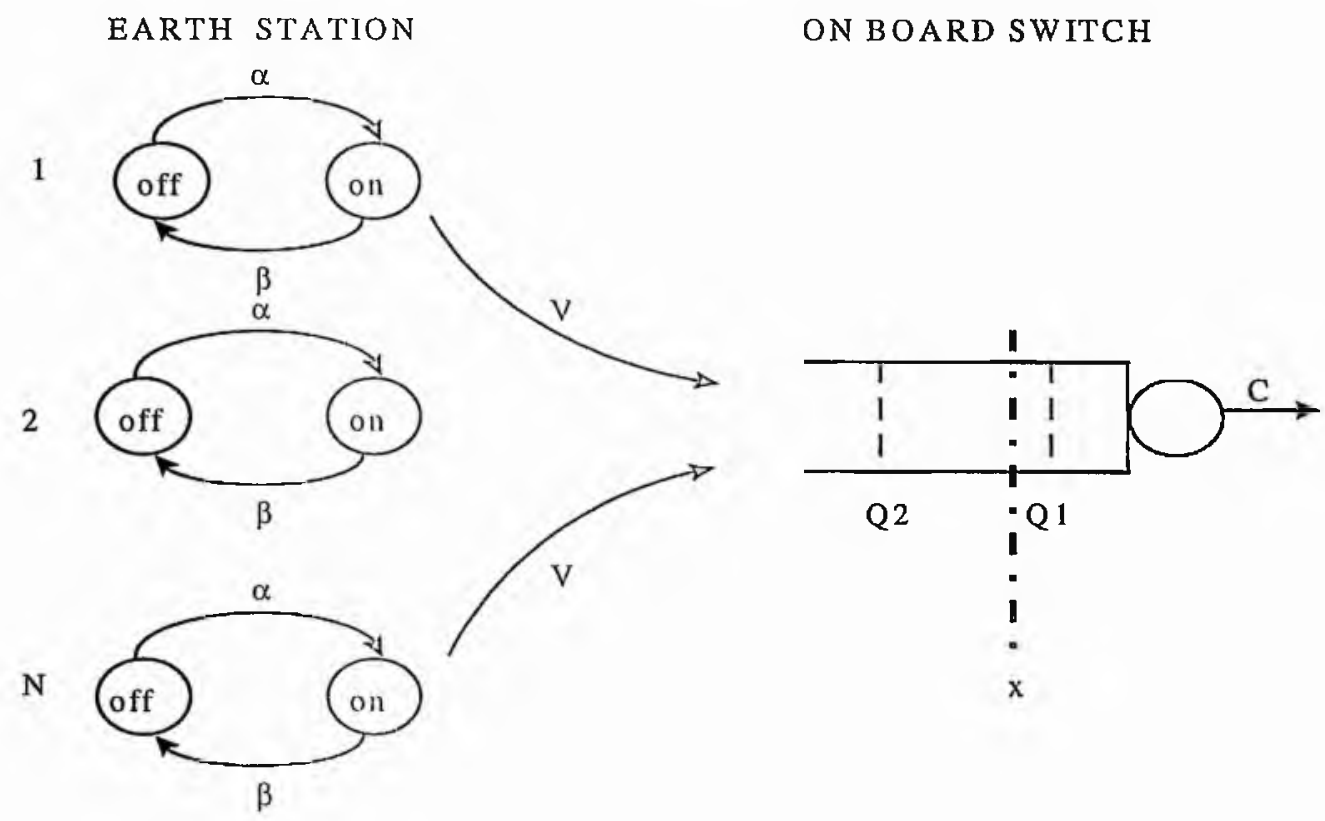

Fig. 4.4 On board Traffic Model

Each on-off source transmits cells during its (on) period. The parameter $\alpha, \beta$ represents the rate of transition out of (off) state and (on) state respectively. $\mathrm{N}$ independent sources are multiplexed, and their average (on) period is distributed exponentially with mean $1 / \beta$, their average (off) period is $1 / \alpha$ in exponential length. Each source generates cells at its peak cell rate(V cells/sec) continuously with (on) state and the average rate of cell is clefined as $\lambda=\alpha /(\alpha+\beta) \mathrm{V}$. We also define the transmission capacity of the satellite on-board as C (cells/sec), the thresholds of the infinite buffer are Q1 (low threshold), Q2 (high threshold), and the variable queue length as $x$.

Another main parameter to describe the sources characteristic is their burstiness. It is defined by the ratio ol peak cell rate to the average cell rate or can be expressed in terms of its burst length as shown in Fig 4-5. 


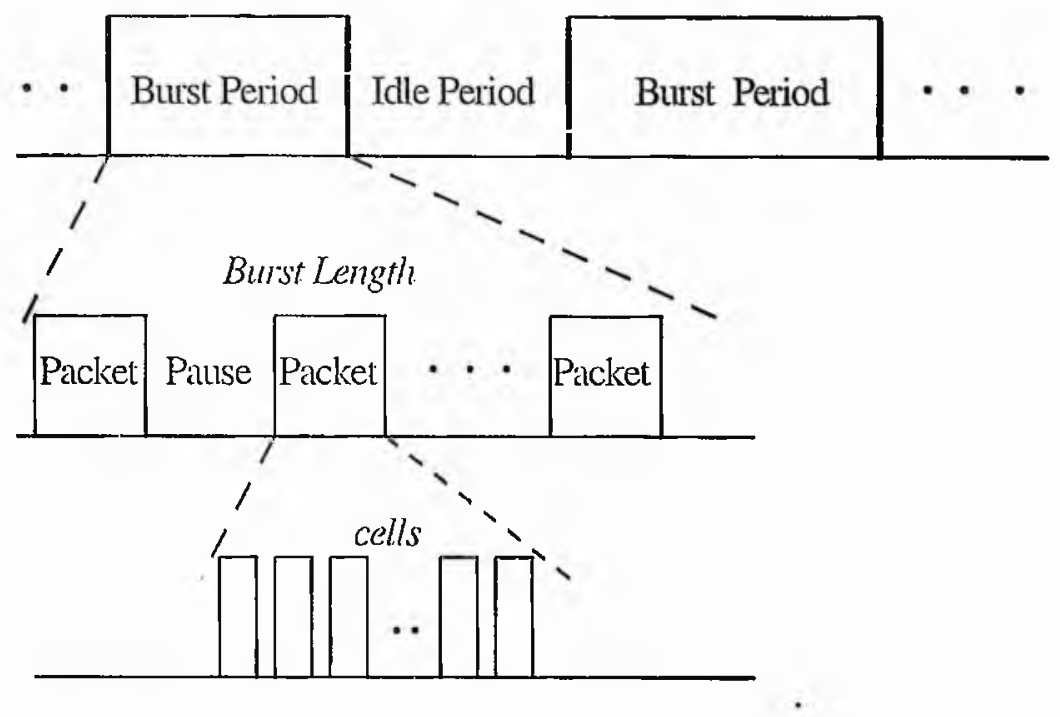

Fig.4-5 Bursty Source Behaviour

$$
\begin{gathered}
b=(\text { burstiness })=P C R / A C R(\text { or } S C R)=(T o+T i) / T o \\
\text { where To }=\text { burst time }(\text { on }- \text { time }), \\
\text { Ti }=\text { idle time }=T o(b-1) .
\end{gathered}
$$

Each burst length has an independent random size because the inter arrival time of source follows negative exponential distributions.

The steady state probability $\pi_{i}$ that the composition source is in state $i$, is easily written by noting that it is just the binomial probability that i of $\mathrm{N}$ two state sources are (on), while the remaining $N-i$ are (off). The probability $\pi_{i}$ is written as

$$
\pi_{\mathrm{i}}=\left(\begin{array}{l}
N \\
i
\end{array}\right)\left(\frac{\alpha}{\alpha+\beta}\right)^{i}\left(\frac{\beta}{\alpha+\beta}\right)^{N-i}
$$

Mathematical approaches usually assume that an individual source is an independent poisson process, the aggregated traffic is also in poisson process whose arrival rate is the summation of the individual rates [28]. If we assume that the length of packet is exponentially distributed, the behaviour of on-board switch buffer can be expressed by a birth and death model. Especially when the model has a single server, the queuing 
model is called a $\mathrm{M} / \mathrm{M} / 1$ quene. Because of the Poisson assumptions involved in two successive time intervals $t$ and $t+\delta t(\delta t \rightarrow 0)$, the buffer could only have occupied one of the three states(N-1,N,N+1). An alternative derivation of equation(4-2), using birthdeath analysis is also useful, particularly in connection with some of analysis for the on-board buffer.

Let $\{\mathrm{X}(\mathrm{t})\}, \mathrm{t}>0\}$ be a continuous parameter. Markov process and the transition probability of two state Markov process $\{X(t)\}$ is defined as follows

$\operatorname{Pij}(t)=P[X(t)=j \mid X(0)=i] \ldots . . i, j=0,1$

Suppose two type of events occur as shown in Fig. 4-4 under the following postulation. Let a "birth" be an event signifying an increase in the population and a "death" be an event that signifies a decrease in the population and consider a sufficiently small interval of time $\delta t$.

(1) Suppose the process $X(t)$ is in state 0 (off state)at time t.

During the infinitesimal interval $(t, t+\delta t)$, the probability that $X(t)$ changes its state from 0 to 1 is $\lambda \delta t+o \delta t$ and the probability remains in state 0 is $1-\lambda \delta t+o \delta t$.

(2) Suppose the process $X(t)$ is in state 1(on state) at time t.

During the infinitesimal interval $(t, t+\delta t)$, the probability that $X(t)$ changes its state from 1 to 0 is $\alpha \delta t+o \delta t$ and the probability remains in state 1 is $1-\alpha \delta t+o \delta t$.

(3) During the time $(t, t+\delta t)$, the probability more than one change of state occurs is oft.

In these postulates we have defined o $\delta \mathrm{t}$ as a "negligible" quantity such that $o \delta \mathrm{t} / \delta \mathrm{t} \rightarrow 0$ as $\delta t \rightarrow 0$, i.e., o $\delta t$ tends to zero much faster than $\delta$. As shown in Fig $4-4$, the buffer occupancy becomes a continuous random variable $\mathrm{x}$. 
In the Appendix-B, the approximation of loss probability of a system and its queue length is derived :

$$
\mathrm{x}=\lambda\left(\frac{\alpha+\beta}{\alpha \beta}\right)\left(\frac{1}{r}\right)(\ln 1 / \mathrm{PL})
$$

$\operatorname{PL}($ cell loss probability $)=e^{-\frac{\beta}{v^{\prime} x}}$

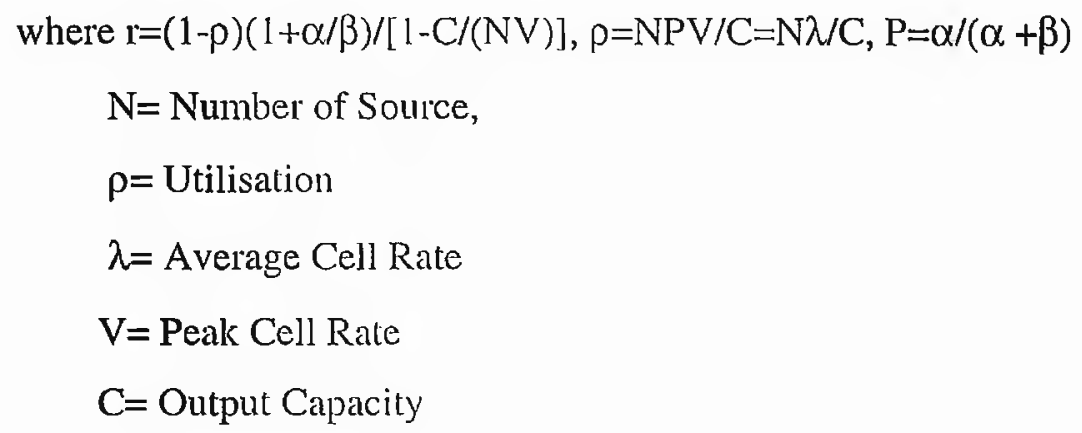




\subsubsection{PROPOSED CONGESTION CONTROL SCHEME}

Based on the traffic model described in previous section, a new congestion control scheme is proposed. The key parameter in this congestion control scheme is queue length of the on-board switch. From equation (4-4), it can be seen that the queue length is a complex function which takes into account parameters such as utilisation, burstiness, cell loss ratio, down link capacity and input rate, etc.

The cells are classified into two types of priority cells : high priority cell and low priority cell. With this different priority policy, the QoS of high priority cells can be guaranteed. In other words, no high priority cells should be lost unless all low priority cells have been discarded. The CBR and VBR cells are given a high priority, whilst $\mathrm{ABR}$ traffic has low priority. It is further assumed that the capacity of high traffic is less than link capacity and ABR capacity only can use the unoccupied capacity left by the high priority traffics.

The congestion states are defined by pre-designed two threshold levels. If the buffer content of the on-board switch exceeds pre-designed thresholds, the control scheme increases or decreases the input $A B R$ rates. The on-board switch compares its queue length to the threshold levels at every control time. All values are measured by a fixed control time. The length of this interval determines the accuracy and variance of the measured quantities. Shorter control provides faster response but results in greater variance.

The Q1 (low queue threshold) is defined as the desired queue threshold which provides a maximum utilisation with reserved $A B R$ cells in the on-board switch buffer. But if it is set too high, the on-board switch may be overflowed because both the high priority traffic and the low priority traffic are time varying. If the down link has idle time due to time varying of high priority traffics, the reserved ABR cells can be transmitted. In this way we can increase the bandwidth utilisation. When we adjust 
the current on-board satellite queue length to Q1, the ABR rate at this instant is called the Desired ABR Rate (Rd) as shown in Fig.4-6.

Then Q2 (high queue threshold) should be designed large enough to guarantee a certain cell loss probability of high priority cells as well as for low priority cells. The suggested congestion control scheme tries to adjust this $Q 1$ and regulate input $A B R$ rate to $\mathrm{Rd}$ at every control time interval.

During the control time interval, the system calculates its average queue length. Instead of the instantaneous status, the average buffer occupancy will be more accurate and effective because it will gather data over a control time and will reduce the measurement errors caused by fluctuations.

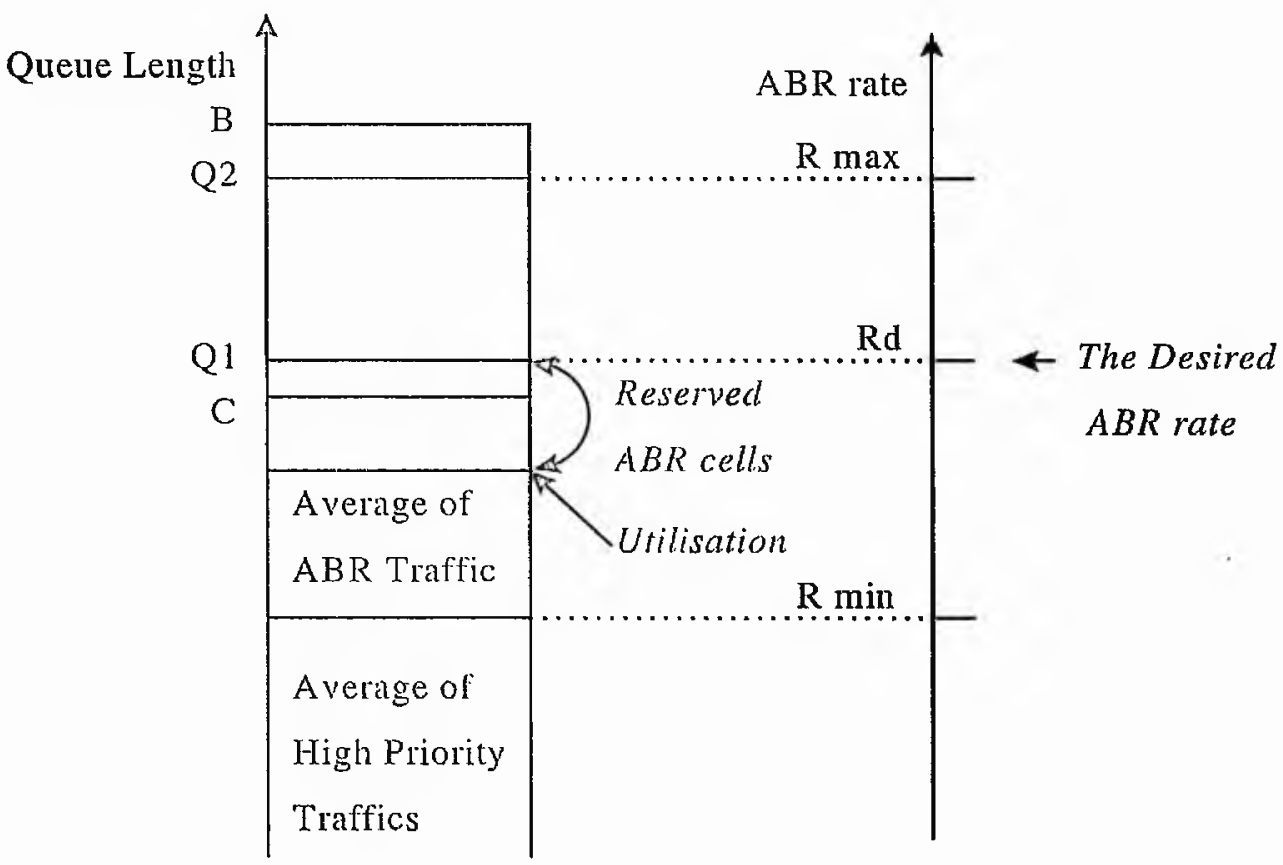

B : buffer size Q1 : desired queue threshold Q2 : high queue threshold $\mathrm{C}$ : link capacity (link rate $\mathrm{x}$ control time) $\mathrm{Rd}$ : desired $\mathrm{ABR}$ rate $\mathrm{R} \max$ : Maximum $A B R$ rate $R$ min: Minimum $A B R$ rate

Fig. 4-6 The Relationship Between $Q 1$ and Rd 
The on-board satellite switch calculates the desired queue length Q1 with the cumulated queue length during the first RTT (Round Trip Time) and the current average arrival rate $R(t 0)$. At the end of every control time interval, on-board satellite switch should determine the congestion states, compute the desired ABR rate, and return them to the ground stations. The desired ABR rate depends on the total capacity of the underlying high priority craffic.

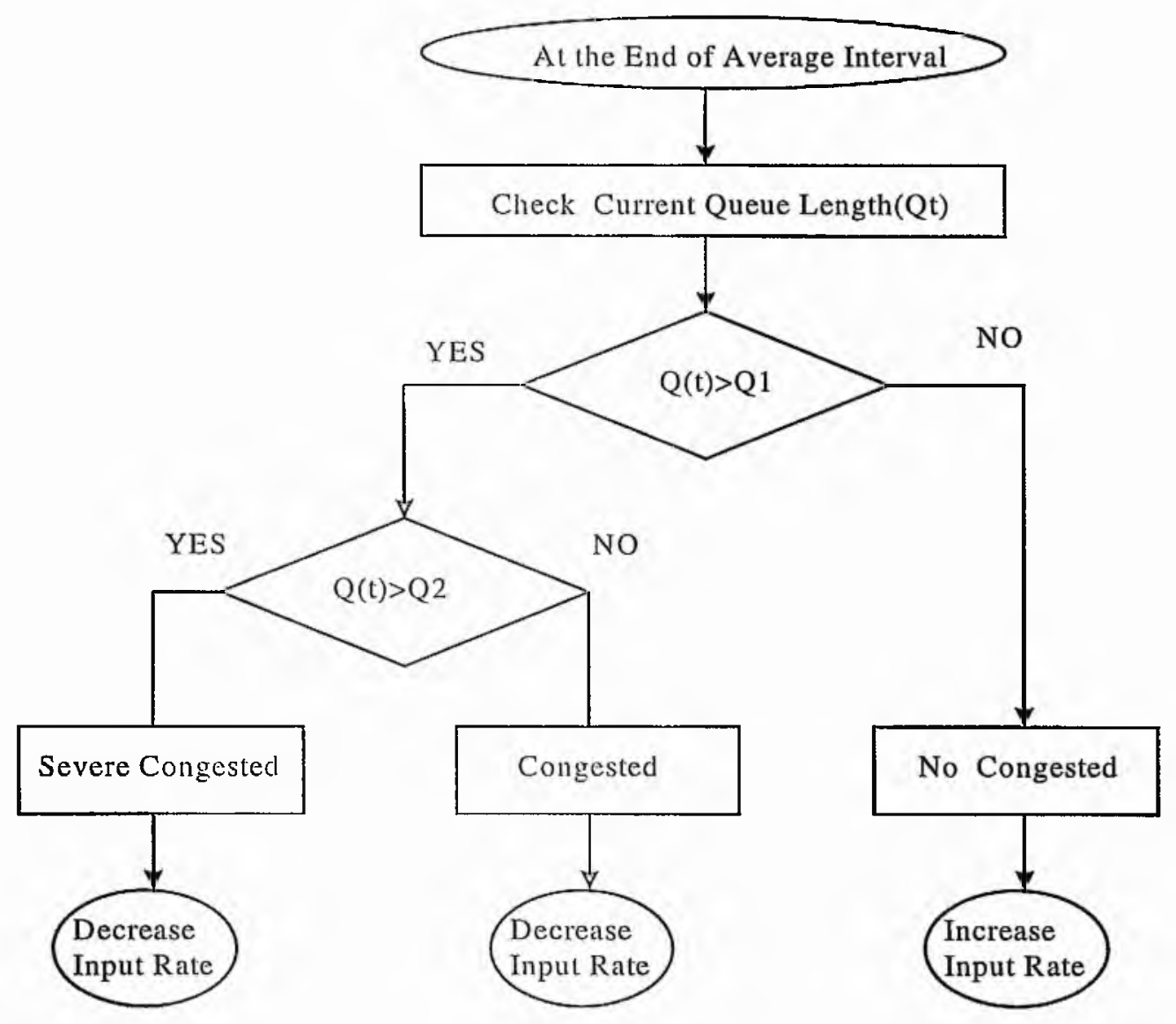

Fig. 4-7 On-board Satellite Switch Behaviour 
According to congestion states, congestion control functions are defined as follows.

The following terms are used in the functions.

$\mathrm{Q}(\mathrm{t})$ : current queue length

Q1 : desired queue threshold(low queue threshold)

Q2 : high queue threshold

$\mathrm{R}(\mathrm{t})$ : current $A B R$ rate

$\mathrm{R}(\mathrm{t}+1)$ : ABR rate of next time slot

$\mathrm{Rd}$ : desired $\mathrm{ABR}$ rate

$\mathrm{z}=\mathrm{d} / \mathrm{c}$ : the ratio of propagation delay to control time

$\mathrm{d}$ : propagation delay

c : control time

$\tau=$ increase factor

$\zeta 1, \zeta 2:$ decrease factors $(\zeta 1<\zeta 2)$

\section{(1) $Q(t)<Q 1$ : No Congested State}

$\rightarrow$ Increase ABR input rate

As shown in Fig. 4-7, if the current queue length $Q(t)$ is less than the desired queue threshold Q1, the on-board satellite switch is in no congestion state. The switch allows the ground stations to increase their ABR rates.

In this case, the control function is as follows :

$$
R(t+1)=R d-[R d-R(t)] e^{-\frac{\tau}{z}}
$$

At the next control time interval, the current $A B R$ rate $R(t)$ will be converged to the desired ABR rate Rd with above control function as shown in Fig. 4-8. The abscissa value of crossing point between the tangent line of graph and $\mathrm{Rd}$ line is $z / \tau$. This means the system which has a small $z$ value or a larger $\tau$ value can be converged 
faster. In order to get small $\mathrm{z}$ value, the propagation delay should be smaller or the control time interval should be larger. Unfortunately, in satellite networks, the long propagation delay is inevitable. If the control time interval is too large, the on-board satellite switch is congested due to the traffic fluctuation. On the contrary, if the control interval is too small, the on-board satellite switch will have an increased processing load and will generate unnecessary load due to the RM cell generation.

Therefore, we need $\tau$, the increase factor parameter, in order to provide a fast response time. The optinisation of these parameters is very important. The impact of these parameters are investigated through simulation means and the results are explained in the following section.

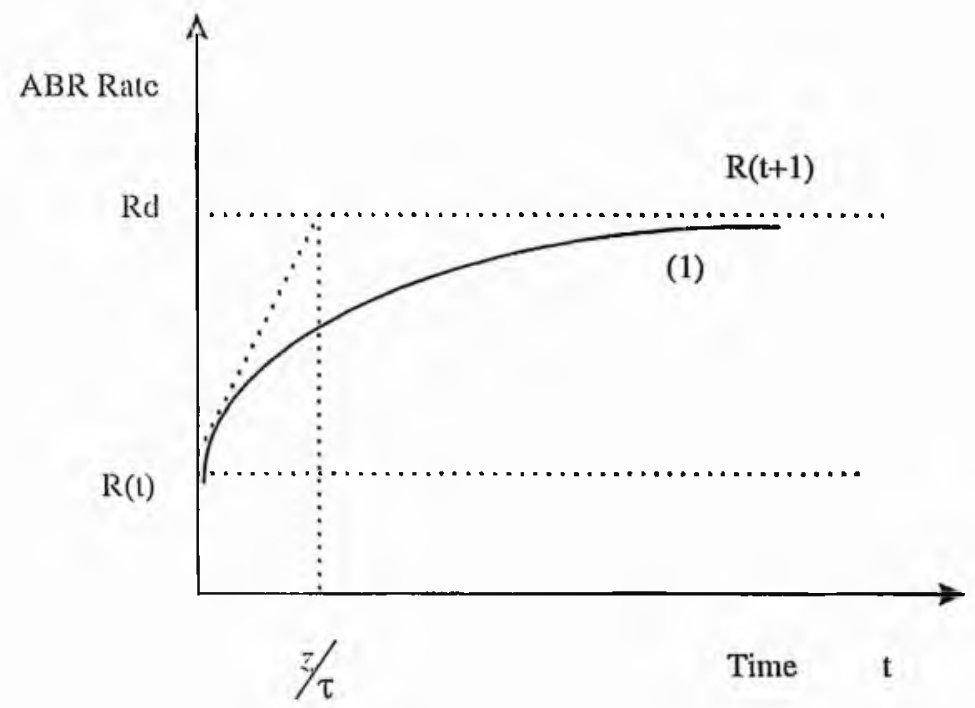

Fig. 4-8 No Congested State

(2) $\mathrm{Q} 1 \leq \mathrm{Q}(\mathrm{t}) \leq \mathrm{Q} 2$ : Congested State

$\rightarrow$ Decrease ABR input rate

If the current queue length $Q(t)$ is between the desired queue threshold $Q 1$ and the high queue threshold $\mathrm{Q} 2$, the on-board satellite switch reduces its $\mathrm{ABR}$ rate to the desired $A B R$ rate. The control function of the congested state is as follows : 


$$
R(t+1)=R d+[R(t)-R d] e^{-\frac{\zeta 1}{z}}
$$

\section{(3) $Q(t)<Q 2$ : Severe Congested State}

$\rightarrow$ Decrease ABR input rate rapidly

If the current queue length $Q(1)$ is larger than the desired queue threshold Q1, the onboard satellite switch is considered in the severe congestion state. The on-board satellite switch should reduce its $A B R$ rate very quickly in order to drain its queue.

The control function of the severe congested state is as follows :

$$
R(t+1)=R d+[R(1)-R d] e^{-\frac{22}{z}}
$$

The difference between the congested and severe congested functions is from two decrease factors. $\zeta 2$ which is larger than $\zeta 1$ can decrease the $A B R$ rate fast as shown in Fig 4-9.

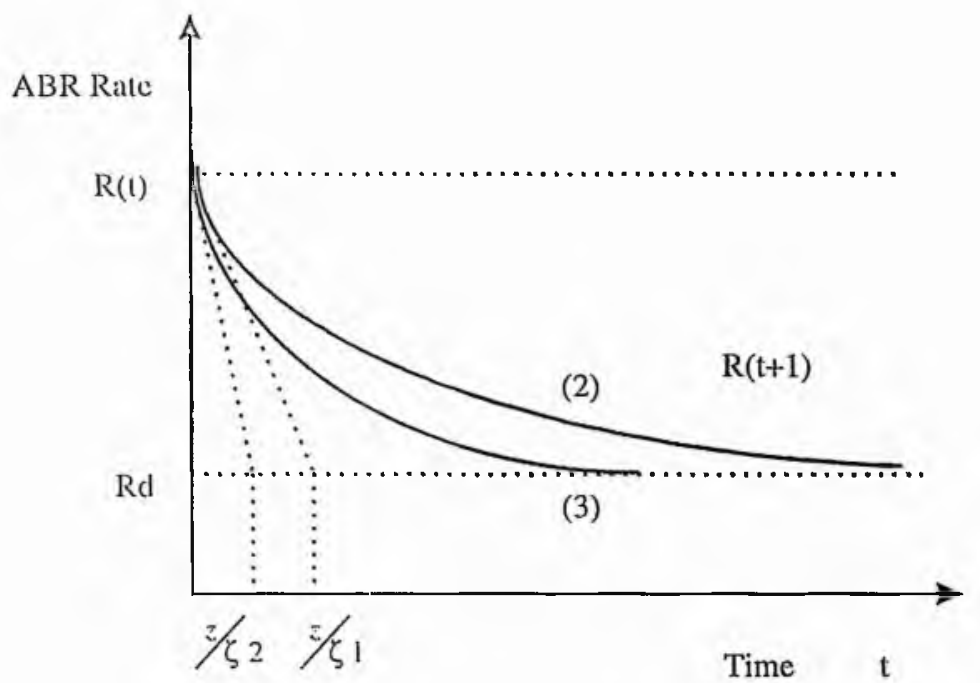

Fig 4-9 Congested State 
During the control time interval, on-board switch can calculate average number of active ABR sources based on the average number of RM cells. Like the ERICA scheme, the suggested congestion control scheme also can achieve fair share among the competing $\mathrm{ABR}$ connections.

$$
\text { FairShare }=\frac{\text { Total Desired ABR Rate }}{\text { Number of Active ABR Sources }}
$$

\subsection{SUMMARY AND CONCLUSION}

In this section, a new congestion control scheme for satellite ATM networks was adopted. The new congestion control scheme has many advantages compared to the conventional congestion control schemes.

First, the new congestion control scheme provides system stability. In order to prevent buffer overflow of the on-board satellite switch, the queue length is adjusted to the desired queue threshold by the control function at every control time interval. Considering the current queue length and the underlying high priority traffic, the onboard satellite switch calculates the desired $A B R$ rate and returns it to the ground stations. But, most of the conventional schemes (PRCA, EPRCA, etc.) do not perform any action until the queue length is out of bound. This causes congestion of the onboard satellite switch, especially in high speed communications.

Second, due to the characleristics of the ABR flow congestion control scheme, the onboard satellite switch utilisation is restricted by the time varying high priority traffic. In order to achieve high utilisation of the switch, the desired queue threshold of the new congestion control scheme is set to slightly above the output capacity. Therefore, the on-board satellite switch always has some reserved ABR cells. If the down link 
slots are idle due to time variation of the high priority traffic, the reserved ABR cells can be transmitted immediately.

Thirdly, the new congestion control scheme has the ratio of delay-control time interval, the exponential increase and decrease parameters. According to the propagation delay, the control time, the increase and decrease factors can be adjusted. Most of the conventional congestion control schemes do not include a propagation delay parameter. Furthermore, if a system has a fixed increase-decrease parameter (eg. EPRCA) or a fixed load factor (eg. ERICA), the system may have a problem to achieve a high switch utilisation because of the underlying high priority traffic fluctuations.

Finally, the response time of the new scheme is very fast because of the exponential equation characteristics. And, the new congestion control scheme provides a system flexibility with various pallameters. In the following section, these advantages offered by the new scheme are shown using simulation means. 


\section{SIMULATION MODELLING AND RESULTS}

\subsection{INTRODUCTION}

In order to evaluate the new congestion control scheme, an OPNET (Optimised Network Engineering Tools) simulation program was implemented as shown in Fig 51.

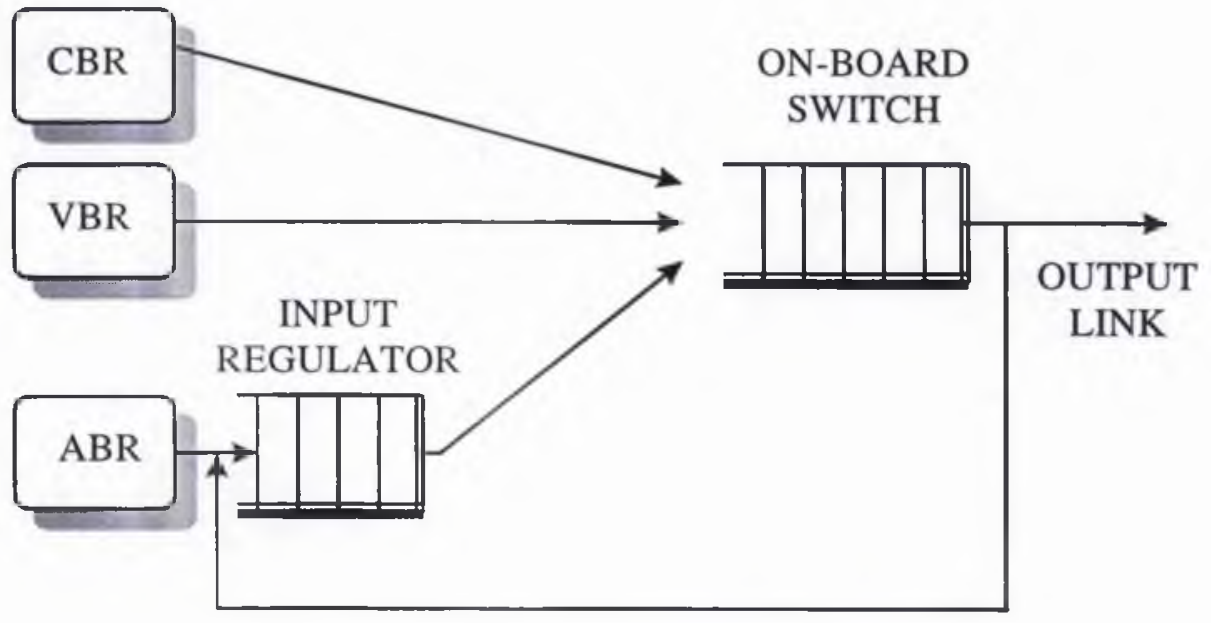

FEEDBACK INFORMATION

Fig. 5-1

Simulation Configuration

The focus of this chapter is to verify the new congestion control functions with different traffic scenarios. The ATM on-board switch is assumed to have a shared buffer. The aggregated multimedia traffic is transmitted continuously from the source to this switch. The traffic model used in this simulation is based on the on-off MMFF model as it was discussed in chapter 4. The CBR and VBR cells are set to high priority and the ABR cells are set to low priority. In other words, if the ATM on-board 
switch is in congested state, the ABR cells will be dropped first in order to guarantee QoS of the high priority cells. At the service schedule process, the high priority cells are processed in advance and then the low priority cells will be sent when the slots are available. It is assumed that the input capacity of the high priority cells (CBR and VBR) is less than the link capacity. The new congestion control scheme in the ATM on-board switch has two queue thresholds and regulates the input ABR rate comparing the current queue length to the queue thresholds. Before evaluating the new control scheme, the effects of the priority, the propagation delay and source behaviour are analysed.

\subsection{SIMULATION MODEL PARAMETERS}

The total input rates are changed according to the utilisation to find out the relationship among the traffic priority, the end-to-end delay and the queue length of the on-board switch with different traffic scenarios, whilst the down link of the onboard satellite switch is fixed at $1,024 \mathrm{kbps}$. The CBR source rate and VBR source rate are also fixed at $64 \mathrm{kbps}$, and $384 \mathrm{kbps}$ respectively. The ABR rate is changed according to the utilisation i.e., utilisation 0.6 ( $\mathrm{ABR}$ rate $=166.4 \mathrm{kbps}$ ), utilisation 0.7 (ABR rate=268.8kpbs), utilisation 0.8 (ABR rate=371.2kbps), utilisation 0.9 (ABR rate $=473.6 \mathrm{bps}$ ) as shown in Table $5-1$. So the $A B R$ rate takes from $27.1 \%$ to $51.4 \%$ of the total input capacity.

The characteristics of the CBR source is assumed to be constant, but that of the VBR and the ABR sources follow a Poisson distribution, which means their burst time is negative exponentially distributed. In addition, the burst duration of each source is generated randomly. To define burstiness of the source is very difficult, because the burstiness of each multimedia application is totally different depending on the source characteristics. The burstiness value is distributed from 1 to several hundreds [21]. In order to simplify the simulation, the mean-burst length is set to burstiness ratio of each source as in [29]. 
Each simulation runs for 200 seconds and the control time was optimised according to the fixed propagation delay. The values used in this simulation are represented as a mean value, such as the input rate, the queue length, etc. The simulation parameters are as follows.

\begin{tabular}{|c|c|c|c|c|}
\hline Parameters & CBR & VBR & $\mathrm{ABR}$ & Description \\
\hline $\begin{array}{l}\text { Total Output Link } \\
\text { Rate(bps),( ):cells/s }\end{array}$ & \multicolumn{3}{|c|}{$1,024,000(2,415)$} & $\begin{array}{l}\text { ABR Input Rates are adjusted } \\
\text { according to the utilisation }\end{array}$ \\
\hline Input Rate(bps) & 64,000 & 384,000 & $166,400(393)$ & $27.1 \%$ Utilisation : 0.6 \\
\hline \multirow[t]{3}{*}{ ():cells/s } & $(150)$ & $(906)$ & $268,800(634)$ & Utilisation : 0.7 \\
\hline & & & $371,200(876)$ & Utilisation : 0.8 \\
\hline & & & $473,600(1,117)$ & $51.4 \%$ Utilisation : 0.9 \\
\hline Packet Size(bits) & 424 & $42 A$ & 424 & ATM cell (53bytes) \\
\hline & & & & \multirow{2}{*}{$\begin{array}{l}0: \text { High priority } \\
\text { 1: Low Priority }\end{array}$} \\
\hline racket Finomity & 0 & 0 & 1 & \\
\hline $\begin{array}{l}\text { Burst Interval } \\
\text { Time Distribution }\end{array}$ & Constant & $\begin{array}{l}\text { Negative } \\
\text { Exponential }\end{array}$ & $\begin{array}{l}\text { Negative } \\
\text { Exponential }\end{array}$ & \\
\hline $\begin{array}{l}\text { Burst Length } \\
\text { Distribution }\end{array}$ & Constant & Poisson & Poisson & \\
\hline $\begin{array}{l}\text { Mean Burst } \\
\text { Length }\end{array}$ & 3 & 10 & 10 & $\begin{array}{l}\text { Average number of generated } \\
\text { cells in an active(on) period }\end{array}$ \\
\hline
\end{tabular}

Table 5-1 Simulation Parameters 


\subsection{SIMULATION RESULTS}

\subsubsection{EFFECT OF TRAFFIC PRIORITY, UTILISATION AND PROPAGATION DELAY}

The first set of simulation runs have been performed to verify the effect of traffic priority, the utilisation and the propagation delay. The propagation delay was set to $125 \mathrm{~ms}$ and $50 \mathrm{~ms}$, in order to consider GEO and MEO systems respectively.

As shown in Fig. 5-2, 5-3, and 5-4, the high priority cells (CBR and VBR cells), have almost the same end to end delay. But the low priority ABR cells suffer from a larger delay, especially at higher loads.

The simulation results in Fig 5-3, 5-4 show that the propagation delay affects the Endto-End delay of each source, equally by a fixed value. That is one RTD (Round Triptime Delay).

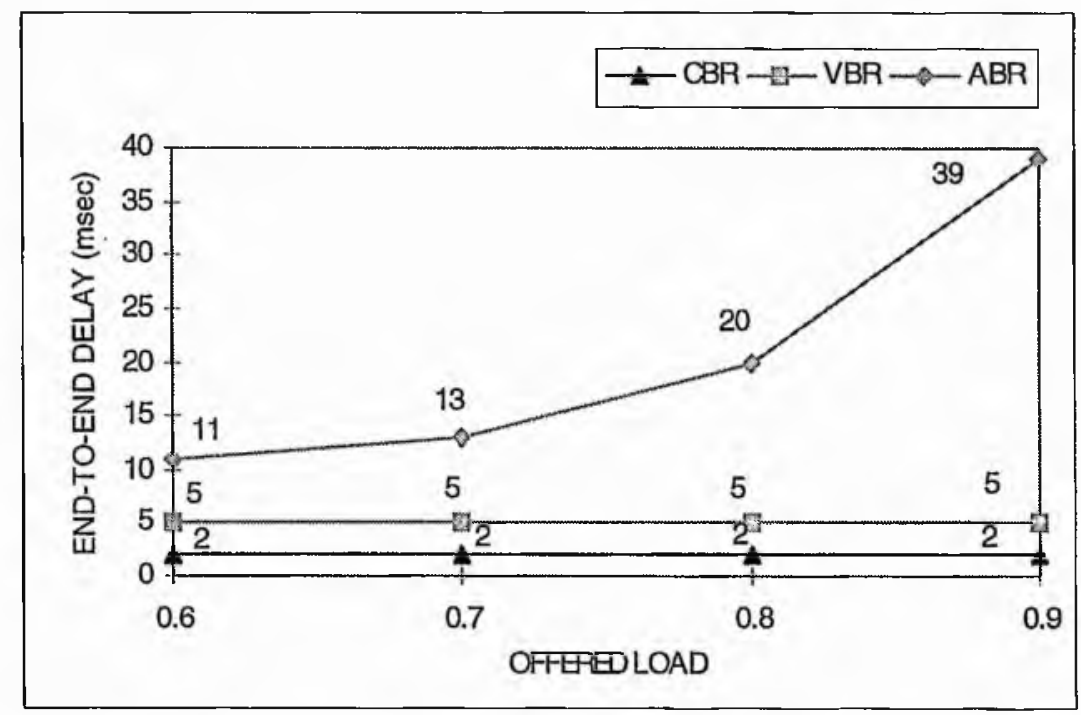

Fig. 5-2 End-to-End Delay (Zero Propagation Delay) 


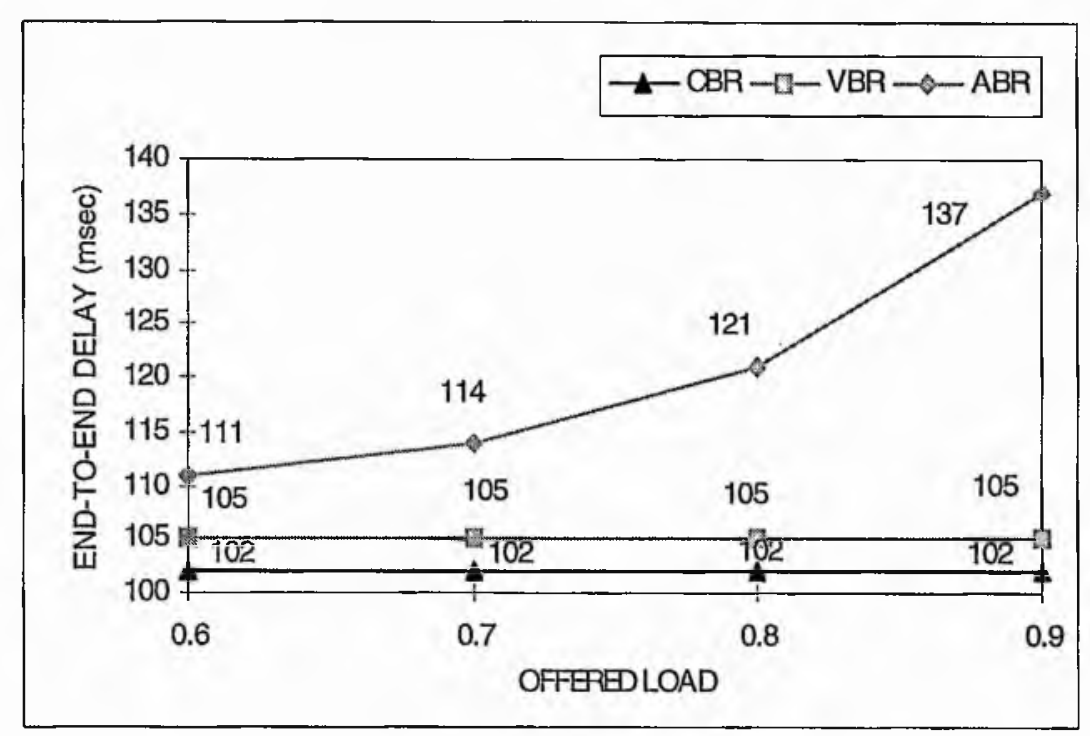

Fig. 5-3 End-to End Delay(Propagation Delay : 50ms)

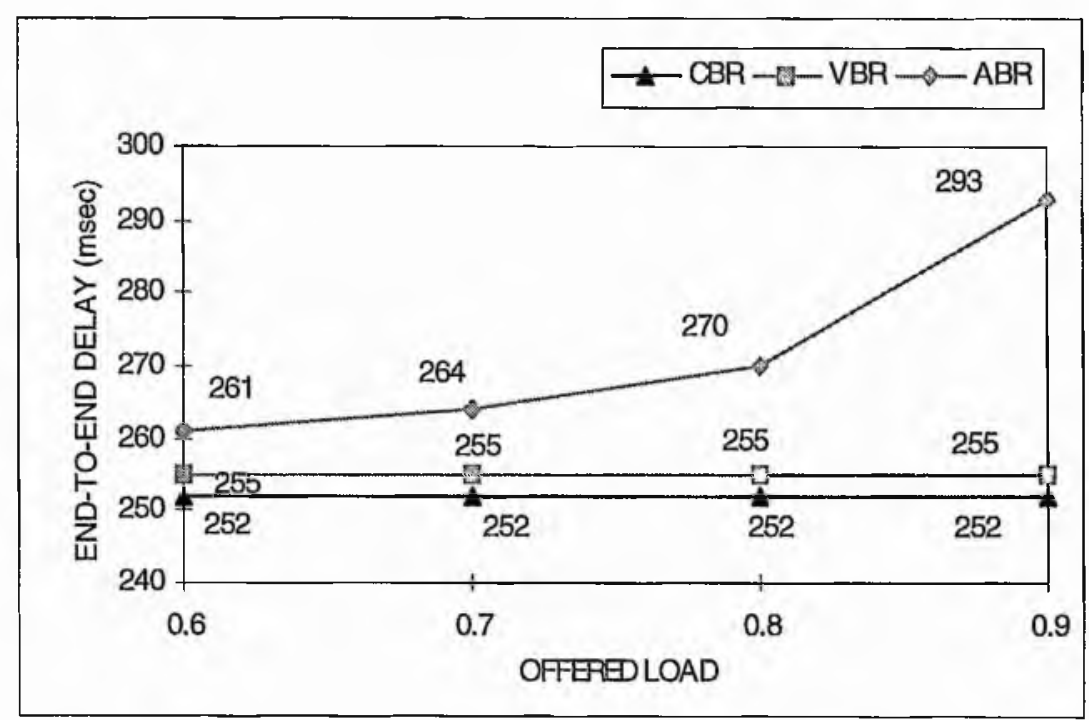

Fig. 5-4 End-to-End Delay (Propagation Delay : 125ms)

As shown in Fig. 5-5, 5-6, 5-7, the queue length of the on-board satellite switch is increased as the load increases. When the traffic load reaches to 1 , the queue length increases rapidly. The propagation delay does not have an impact on the queue length due to the fact that no feedback information is sent to the traffic sources. 


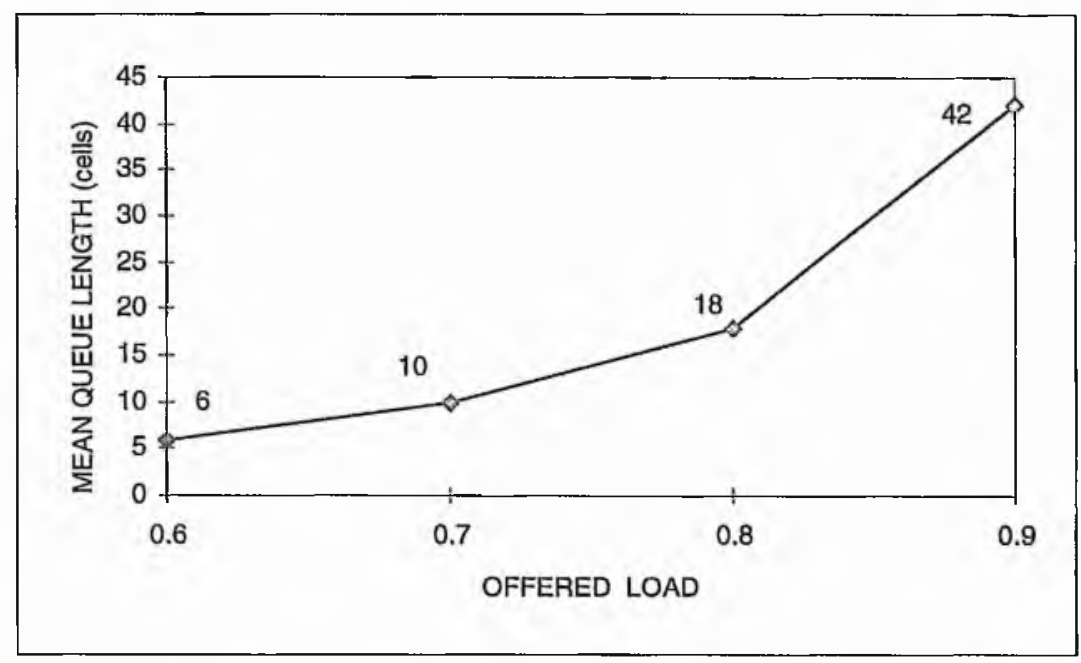

Fig.5-5 Queue Length (Zero Propagation Delay)

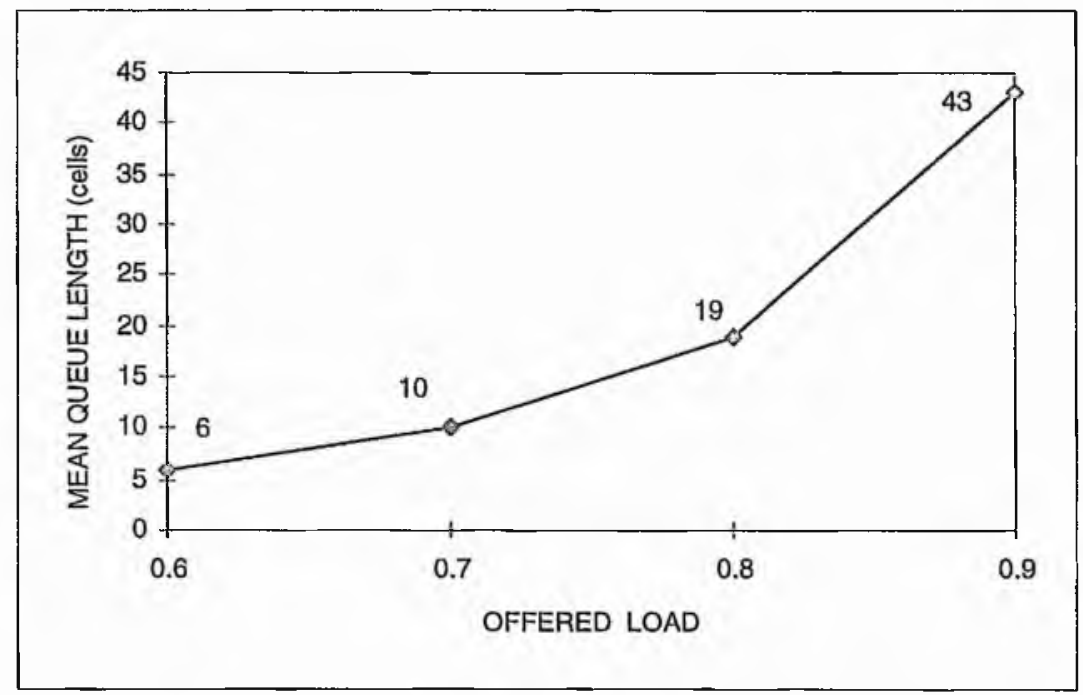

Fig.5-6

Queue Length (Propagation Delay : 50ms) 


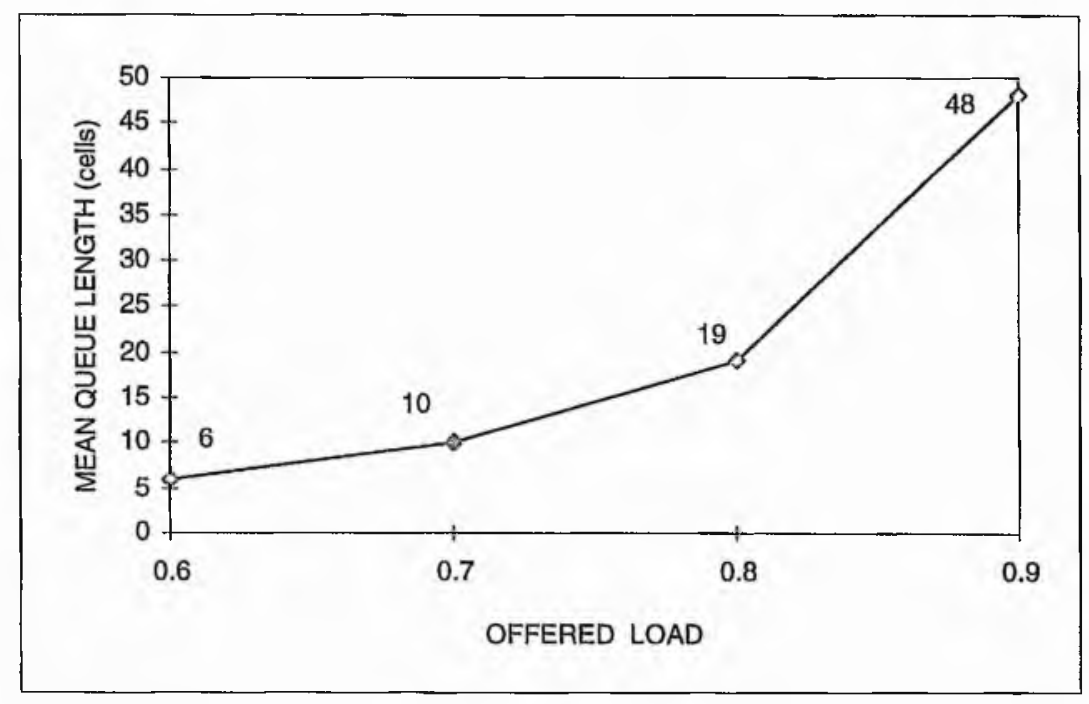

Fig.5-7

Queue Length (Propagation Delay : 125ms)

\subsubsection{EFFECT OF SOURCE BEHAVIOUR}

The second set of simulation runs have been performed to find the effect of burstiness of the input sources.

In order to check the effect of burstiness, $A B R$ burstiness of 20,50,100 was assumed whilst keeping the CBR and VBR sources unchanged. The End-to-End delay and the queue length for each case was compared with different propagation delays $(50 \mathrm{~ms}$, 125ms). Fig. 5-8, 5-9, 5-10, 5-11 show that the queue length and the End-to-End delay are increased as the burstiness of the ABR source increases. A high value of burstiness increases considerably the queuing delay and the End-to-End transmission delay, especially for long propagation delays. 


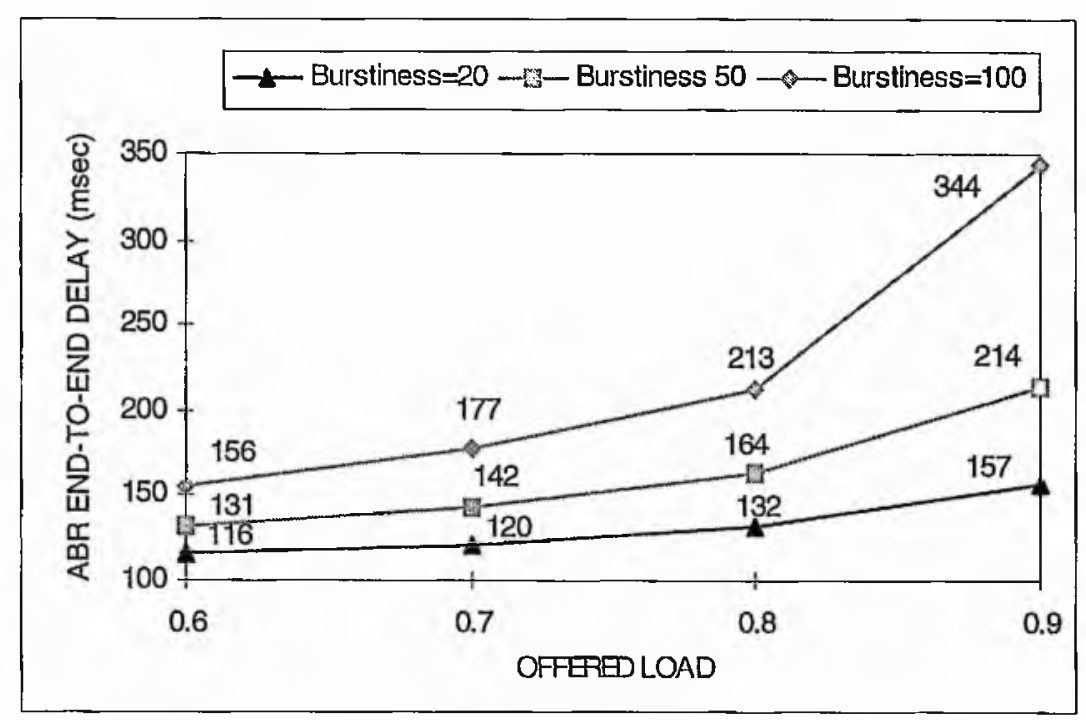

Fig. 5-8 Burstiness \& ABR End-to-End Delay(Propagation Delay : 50ms)

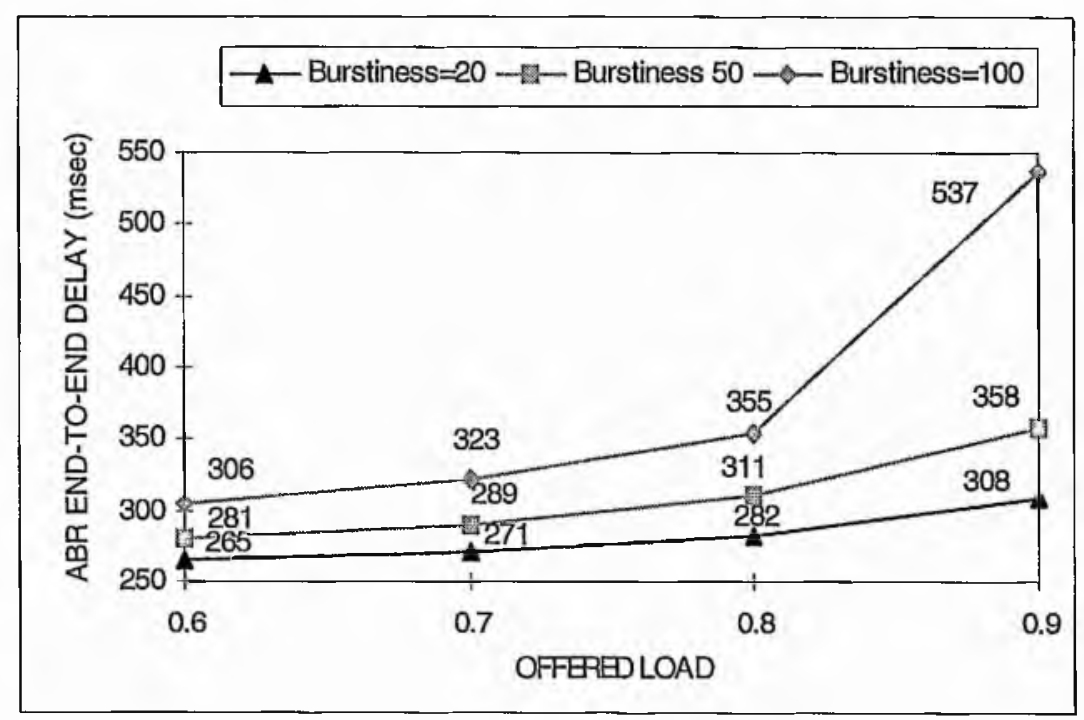

Fig. 5-9 Burstiness \& ABR End-to-End Delay(Propagation Delay : 125ms) 


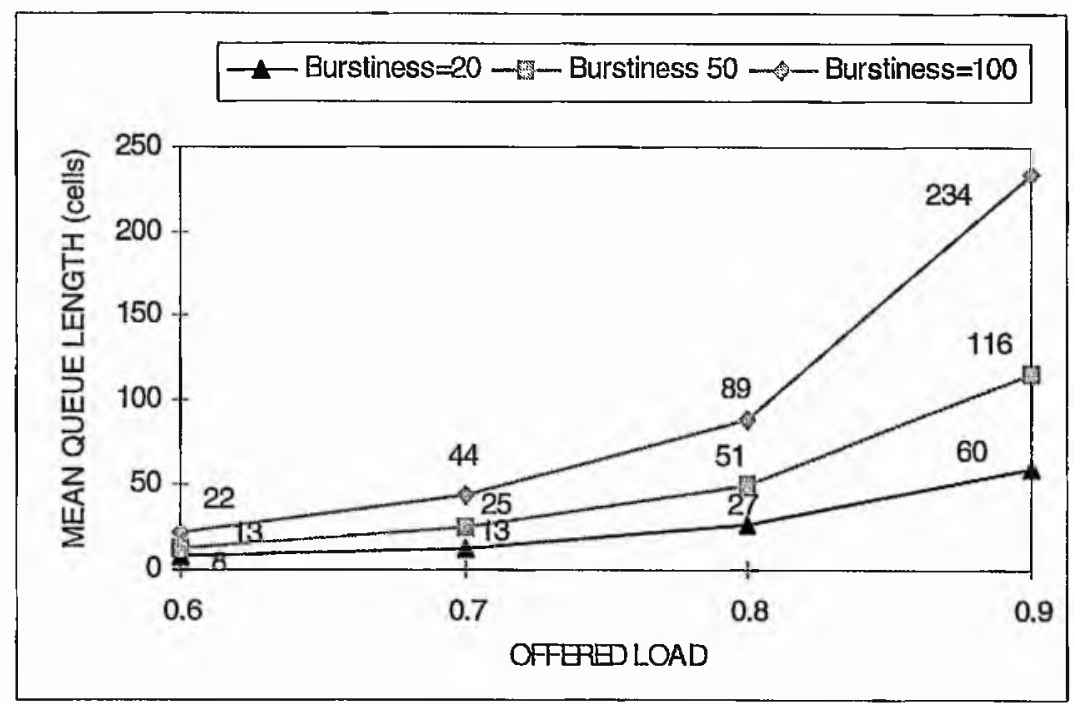

Fig. 5-10 Burstiness \& Queue Length (Propagation Delay : 50ms)

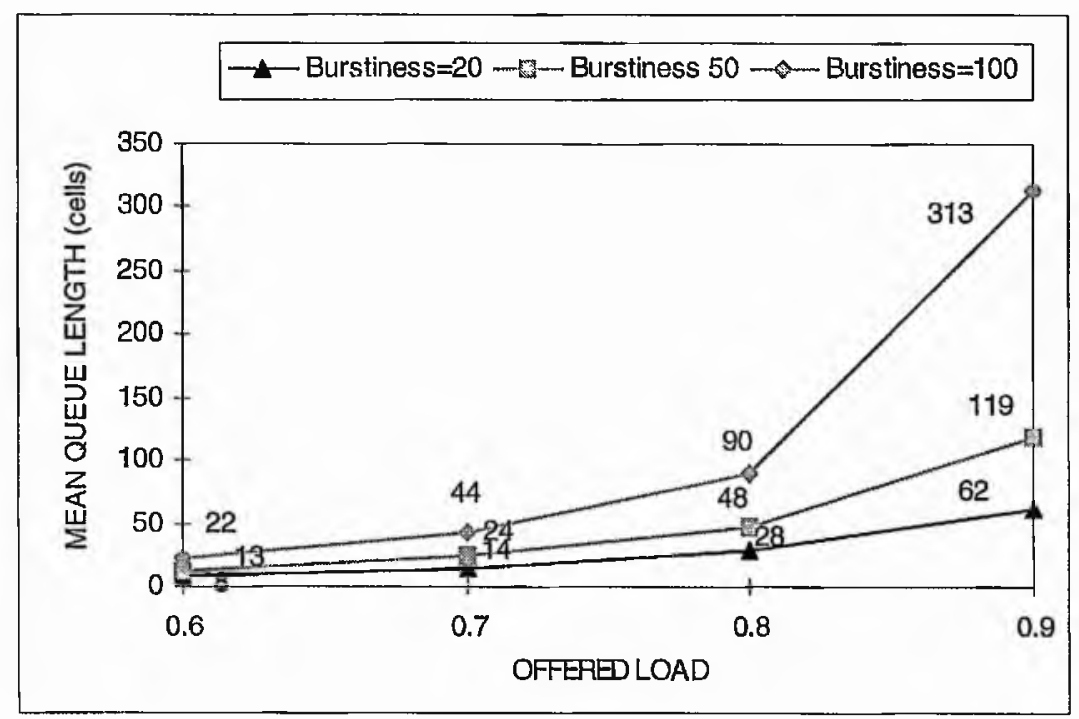

Fig. 5-11 Burstiness \&Queue Length(Propagation Delay : 125ms) 


\subsubsection{EFFECT OF THE CONGESTION CONTROL FUNCTION}

The third set of simulation runs have been performed to illustrate the effect of the congestion control function. We used an offered load of 0.6, 0.9 and the propagation delay of $125 \mathrm{~ms}$. The low queue threshold was set to 10 cells, and the high queue threshold to 30 cells. The on-board satellite switch control function calculates its queve length at every control time interval and compares it to the desired threshold. According to the current queue length, the control function advises the ABR source to increase or decrease its input rate.

As shown in Fig. 5-12, 5-13, 5-14, the control function of the new algorithm performs quite well. It keeps the queue length around the desired queue threshold (low threshold) with QoS guarantees for the high priority cells. The average queue length is 10 cells at the offered load of 0.9 and 8 cells at the offered load of 0.6 .

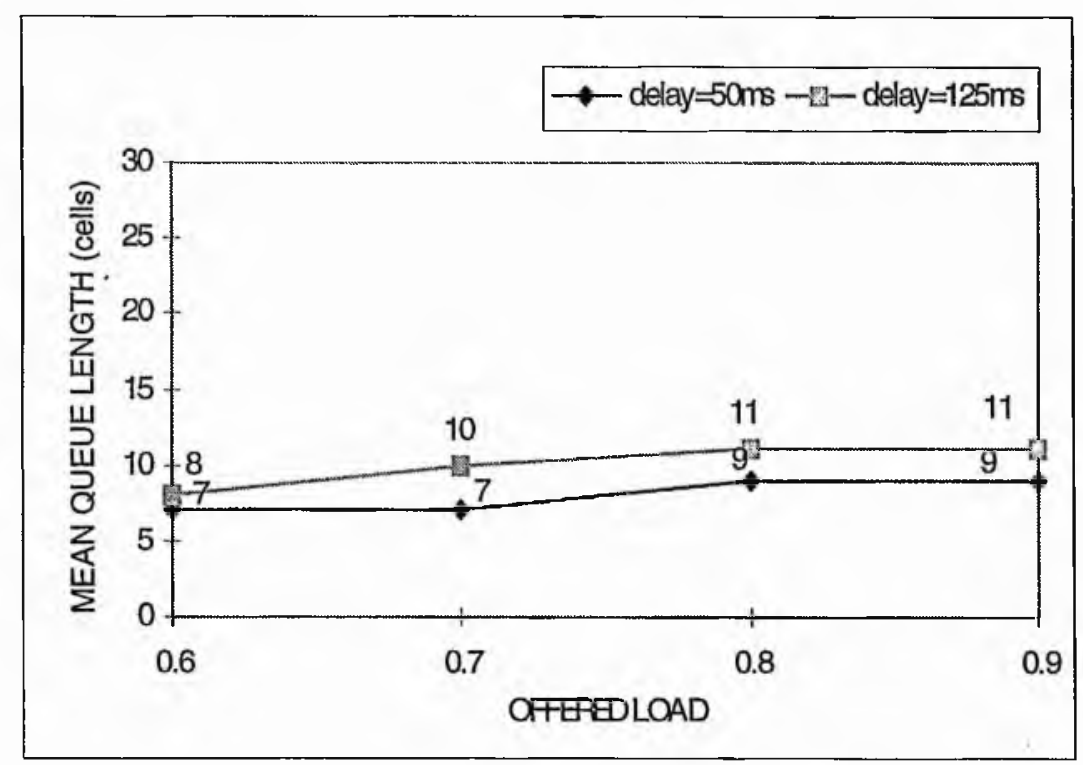

Fig. 5-12 Queue Length with the New Control Function 


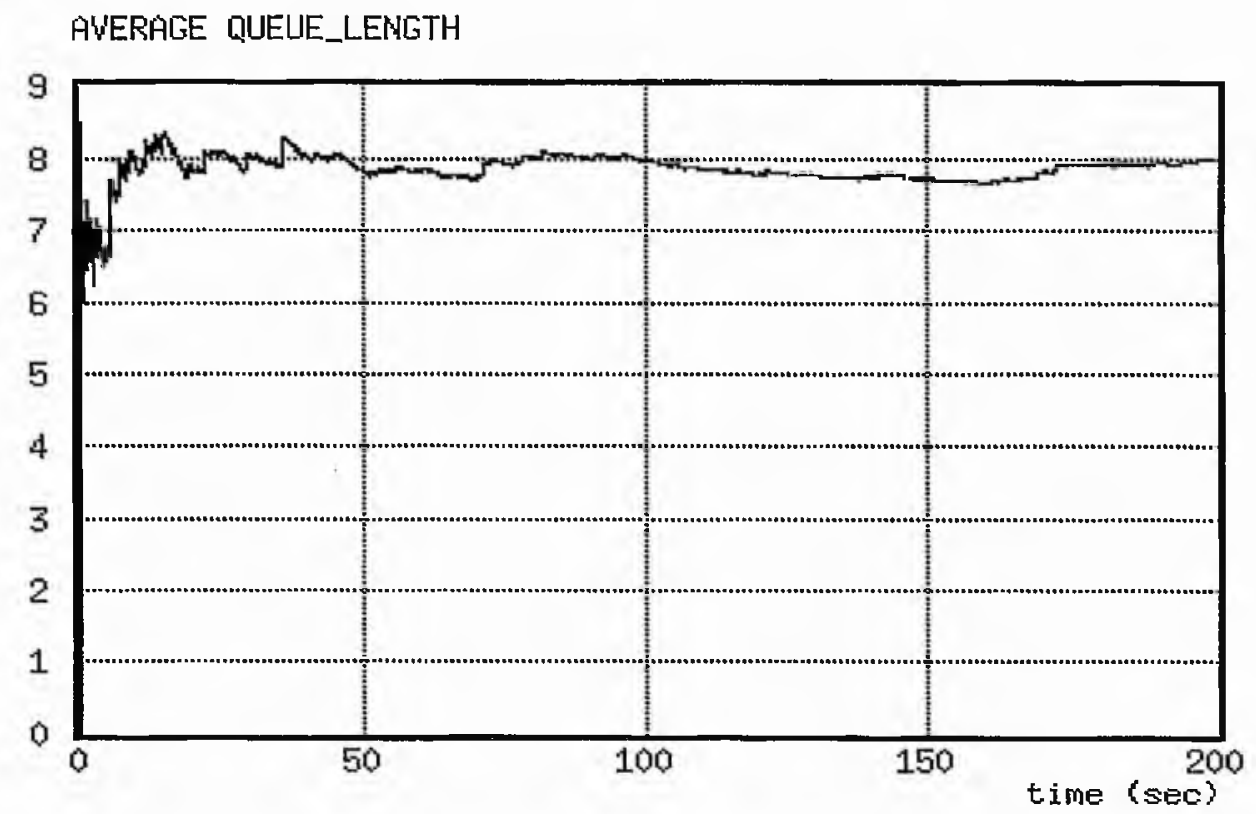

Fig. 5-13 Queue Length (Offered Lad:0.6)

ANERAGE QUEUUE_LENGTH

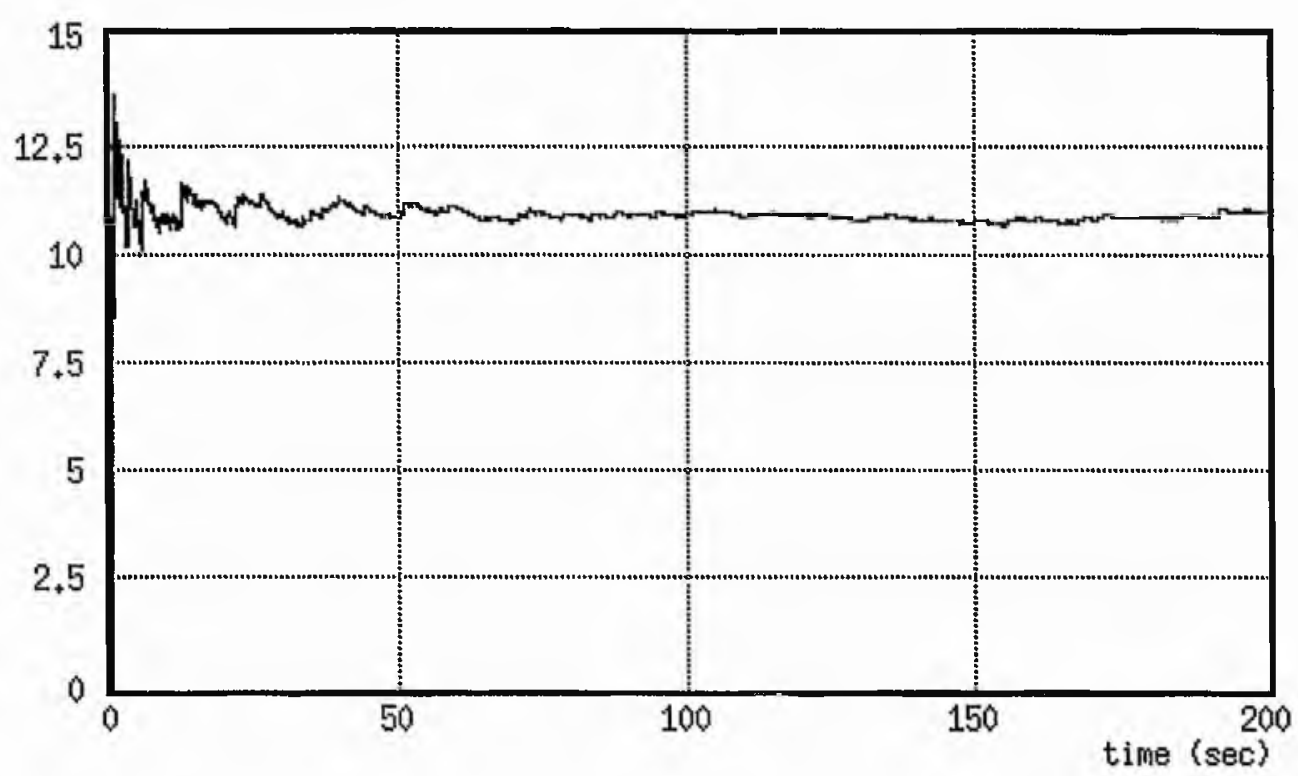

Fig. 5-14 Queue Length (Offered Load: 0.9) 
In order to adjust the current queue length to the desired queue threshold, the $A B R$ rate of the offered load 0.9 case is decreased from 1,117 cells/s to 910 cells/s (about 9\%). On the contrary, in the 0.6 offered load case, the ABR rate is increased from 393 cells/s to 780 cells/s (about 100\%) as shown in Fig. 5-15, 5-16. After the transition time $(8 \mathrm{sec}, 10 \mathrm{sec})$, the input rates of the system are in the stable state.

$A B R \_$input rate (cells/s)

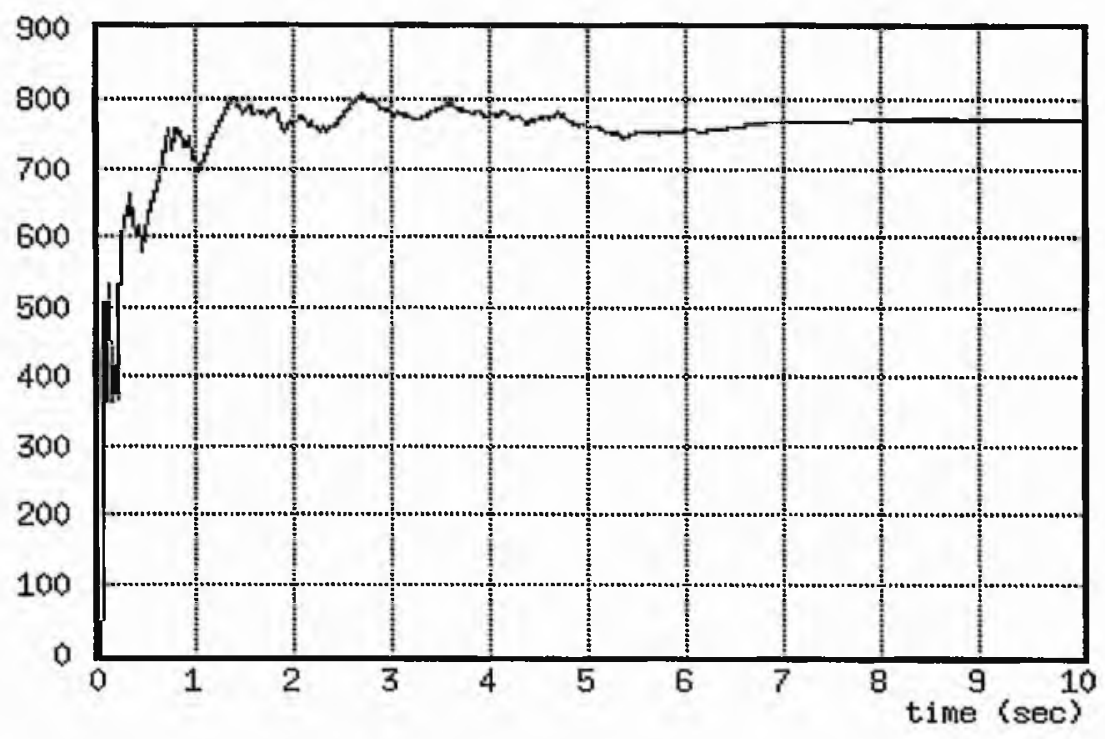

Fig. 5-15 ABR Input Rate(Offered Load : 0.6) 


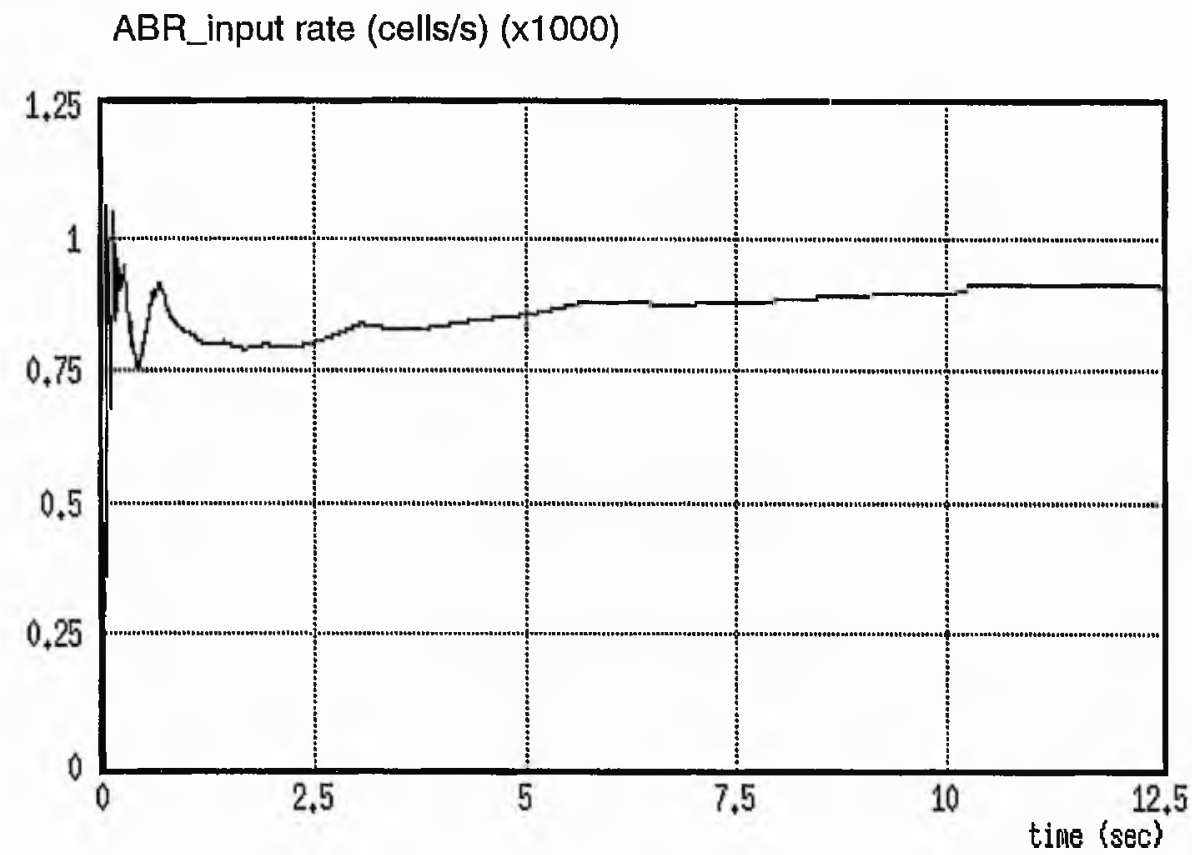

Fig. 5-16 ABR Input Rate(Offered Load: 0.9) 


\subsubsection{EFFECT OF THE CONTROL TIME INTERVAL, INCREASE}

\section{AND DECREASE FACTORS}

The control time interval has a great impact on ABR QoS. To lessen this impact, we need shorter control time intervals, but it may be a burden on the switch. In a large propagation delay system, the relationship between guaranteeing QoS and control time intervals are system design trade offs. If the control time is fixed, one can optimise the increase and decrease factors in the congestion control system.

For example, in the 0.6 offered load case, the ABR input rate will be increased from 393 cells/s to 780 cells/s. But the response time depends on the control parameters. Let us set $\mathrm{k}=(\mathrm{c} / \mathrm{d}) \tau$, a larger $\mathrm{k}$ can increase the $\mathrm{ABR}$ input rate faster. This is closely related to the complexity and cost in the system design. Fig. 5-17 shows that if the parameter $\mathrm{k}$ is over 4 , the response time of the system is very fast.

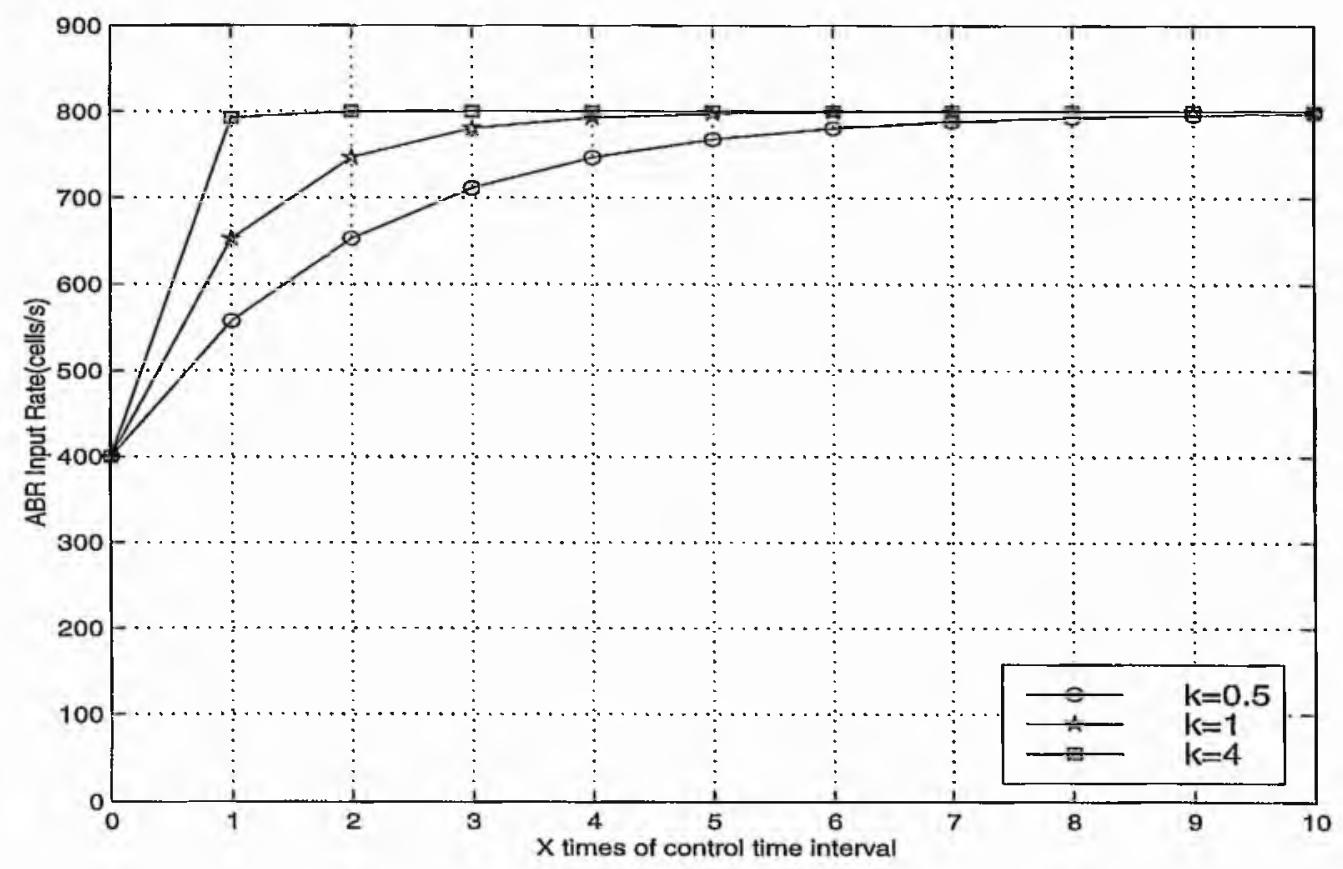

Fig. 5-17 The Relationship between Response Time and Control Parameters 


\subsection{FEATURES OF THE SUGGESTED CONGESTION CONTROL SCHEME}

The suggested congestion control scheme has many advantages comparing to the conventional congestion schemes.

- Obtains system stability with the desired queue length

- The ABR input rate is adjusted directly to the desired ABR rate at every control time interval

- Achieves fast response time with exponential increase and decrease functions

- Increases utilisation by keeping the desired queue threshold with the reserved ABR cells (back-log cells) in the buffer

- Prevents buffer overflow in a system with long propagation delay

- It can be adjusted into various traffic conditions 


\section{CONCLUSIONS AND FUTURE STUDY}

There are many issues in designing ATM on-board satellite switches for the provision of broadband multimedia services. The most challenging one was to reduce the impact of the long propagation delay in a rate adaptive service class such as the ABR ATM class.

The proposed scheme uses a reactive $A B R$ feedback control signal to regulate the desired input traffic. This study shows that it is possible to overcome the long propagation delay in a satellite communication network with adaptive control schemes.

This new control scheme allows high link utilisation, maintains the desired queue length and provides fast response times. The performance evaluation of the scheme was conducted using a simple satellite traffic model. This work could be extended by introducing more sophisticated traffic models into the basic satellite model and test the new algorithm under various mixed traffic scenarios that include self similar traffic. 


\section{REFERENCES}

[1] B. Le Stradic, et al., "The West Project : Exploiting the Ka Band Spectrum to Develop the Global Information Infrastructure", Second Ka Band Utilisation Conference, Florence, Sept., 1996.

[2] ATM Forum, “Traffic Management Specification”, Version 4.0, Apr., 1996.

[3] Ra'ed Y. Awdeh, H.T Mouftah, "Survey of ATM Switch Architectures", Computer Networks and ISDN Systems, Vol.27, 1995.

[4] Othmar Kyas, "ATM Network : Second Edition", International Thomson Computer Press, London, 1997.

[5] Achille Pattavina, "Switching Theory : Architectures and Performance in Broadband ATM Networks", John Wiley \& Sons, Chichester, 1998.

[6] Flavio Bonomi, Kerry W. Fendick, "The Rate-Based Control Framework for the Available Bit ATM Service", IEEE Network, Mar., 1995.

[7] Martin de Prycker, "Asynchronous Transfer Mode : Solution for Broadband ISDN", Prentice Hall Int'. Ltd., 1995.

[8] Shiv Kalyanaraman, et al., "The ERICA Switch Algorithm for ABR Traffic Management in ATM Networks", IEEE Transaction on Network, Nov., 1997.

[9] H. T. Kung and Robert Morris, "Credit Based Flow Control for ATM Networks", IEEE Network Magazine, Mar., 1995.

[10] Raj Jain, "Congestion Control and Traffic Management in ATM Networks : Recent Advances and A Survey", Computer Networks and ISDN Sys., Vol. 28, Oct., 1995.

[11] Raj Jain, et al., "ERICA Switch Algorithm : A Complete Description", http://www.cis.ohio-state.edu/ jain/papers.html.

[12] Bobby Vandalore, et al., "Design and Analsis of Queue Control Functions for Explicit Rate Switch Scheme", http://www.cis.ohio-state.edu/ jain/papers.html.

[13] Pierluigi Adami, et al., "Ground Segment Architecture for Ka-band Multimedia Satellite System", Second Ka Band Utilisation Conference, Florence, Sept., 1996. 
[14] Kaveh Pahlavan, Ali Zahedi, and Prashant Krishnamurthy, "Wideband Local Access : Wireless LAN and Wireless ATM", IEEE Transactions on Communications, Nov, 1997.

[15] Ian F. Akyildiz, Seong-ho Jeong, "Satellite ATM Network : A Survey", IEEE Communications Magazine, Jul., 1997.

[16] G. Maral, M. Bousquet, "Satellite Communications Systems, Techniques and Technology 2nd Edition", John Wiley \& Sons, Inc., Feb., 1996.

[17] Nikos Passas, et al., "Quality of Service Oriented Medium Access Control for Wireless ATM Networks", IEEE Communications Magazine, Nov., 1997.

[18] Osama Kubbar, Hussein T. Mouftah, "Multiple Access Control Protocols for Wireless ATM : Problems Definition and Disign Objectives", IEEE Communications Magazine, Nov., 1997.

[19] Dipankar Raychaudhuri, et al., "A Prototype Wireless ATM System for Multimedia Personal Communication”, IEEE JSAC, Vol.15, No. 1, Jan., 1997.

[20] Partho Pratim Mishra, et al., "On Hop-by-hop Rate-Based Congestion Control", IEEE/ACM Transactions on Networking, Vol. 4, No. 2, Apr., 1996.

[21] Raif O. Onvural, "Asynchronous Transfer Model Network : Performance Issues", Artech House, Boston/London, 1994.

[22] J. M. Pitts, J. A. Schormans, "Introduction to ATM Design and Performance", John Wiley \& Sons, Chichester, 1996.

[23] Anick. et al., "Stochastic Theory of a Data Handling System with Multiple Source”, Bell System Tech. J., Oct. 1982.

[24] Yuming Liu and Peter J. Molan, "Multi-Level Threshold for Priority Buffer Space Management in ATM Networks", IEEE INFORCOM '96, 1996.

[25] Roch Guerin, "Equivalent Capacity and Its Application to Bandwidth Allocation in High-Speed Networks", IEEE JSAC, Vol. 9, No. 7, Nov.1991.

[26] W.K. Tsai and Y. Ge, "Stability Analysis of Intelligent Marking EPRCA for Congestion Control in ATM', IEEE INFORCOM '97, Apr., 1997.

[27] Pong P Chu, William D. Irancic and Heechul Kim, "On-board Closed-Loop Congestion Control for Satellite-based Packet Switching Networks", Journal of Satellite Communications, Vol.12, May. 1994. 
[28] Mischa Schwartz, "Broadband Integrated Networks", Prentice Hall PTR, 1996.

[29] Andrea Baiocchi, M. Listanti, “ An ATM like System Architecture for Satellite Communication including On-board Switching", Int' J. of Satellite Communications, Vol. 14, 1994. 


\section{APPENDIX-A : SOURCE, DESTINATION AND SWITCH BEHAVIOUR \\ IN ATM TRAFFIC MANAGEMENT}

\section{SOURCE BEHAVIOUR}

1-1. The value of ACR shall never exceed PCR, nor shall it ever be less than MCR. The source shall never send in-rate cells at a rate exceeding ACR. The source may always send in-rate cells at a rate less than or equal to ACR.

1-2. Before a source sends the first cell after connection set up, it shall set ACR to at most ICR. The first in-rate cell sent shall be a forward RM cell.

1-3. After the first in-rate forward RM cell, in-rate cells shall be sent in the following order;

a) The next in-rate cell shall be a forward RM cell if and only if, since the last in-rate forward RM cell was sent, either;

i) at least Mrm in-rate cells have been sent and at least Trm time has elapsed, or

ii) Nrm-1 in-rate cells have been dent.

b) The next in-rate cells shall be a backward RM cell if condition (a) above is not met, if a backward RM cell is waiting for transmission, and if either;

i) no in-rate backward RM cell has been sent since the last in-rate forward RM cell, or

ii) no data cell is waiting for transmission.

c) The next in-rate cell sent shall be a data cell if neither condition (a) nor condition (b) above is met, and if a date cell is waiting for transmission.

1-4. Cells sent in accordance with source behaviours \#1, \#2, \#3 shall have CLP=0.

1-5, Before sending a forward in-rate RM cell, if ACR $>$ ICR and the time $T$ that has elapsed since the last in-rate forward in-rate was sent is greater than ADTF, then ACR shall be reduce to ICR. 
1-6. Before sending forward an in-rate forward RM-cell, and after following behaviour \#5 above, if at least CRM in-rate forward RM cells have been sent since the last backward RM cell with $\mathrm{BN}=0$ was received, then $\mathrm{ACR}$ shall be reduced at least $A C R * C D F$, unless that would result in a rate below MCR, in which case ACR shall be set to MCR.

1-7. After following behaviours \#5 and \#6 above, the ACR value shall be placed in the CCR field of the outgoing forward RM cell, but only in-rate cells sent after the outgoing forward RM cell need to follow the new rate.

1-8. When a backward RM cell(in-rate or out-of-rate) is received with $\mathrm{CI}=1$, then ACR shall be reduced by at least $A C R^{*} \mathrm{RDF}$, unless that reduction would result in a rate below MCR, in which case ACR shall be set to MCR. If the backward RM cell has both $\mathrm{CI}=0$ and $\mathrm{NI}=0$, then the $\mathrm{ACR}$ may be increased by no more than $\mathrm{RIF}{ }^{*} \mathrm{PCR}$, to a rate not greater than PCR. If the backward RM cell has $\mathrm{NI}=1$, the ACR shall not be increased.

1-9. When a backward RM cells (in-rate or out-of-rate) is received, and after ACR is adjusted according to source behaviour \#8, ACR is set to at most the minimum of ACR as computed in source behaviour \#8, and the ER filed, but no lower than MCR.

1-10. When generating a forward RM cell, the source shall assign values to the various RM cell fields as specified for source-generated cell.

1-11. Forward RM cells may be sent out-of-rate(ie., not conforming to the current ACR). Out-of-rate forward RM cells shall not be sent at a rate greater than TCR.

1-12. A source shall reset EFCI on every data cell it sends,

1-13. The source may implement a use-it-or-lost-it policies. 


\section{DESTINATION BEHAVIOUR}

2-1. When a data cell is received, its EFCI indicator is saved as the EFCI state of the connection.

2-2 On receiving a forward RM cell, the destination shall turn around the cell to return to the source. The DIR bit in the RM cell shall be changed from forward to backward, BN shall be set to zero, and CCR, MCR, ER, CI, and NI fields in the RM cell shall be unchanged except;

a) If the saved EFCI state is set, then the destination shall set $\mathrm{CI}=1$ in the $\mathrm{RM}$ cell, and

the saved EFCI state shall be reset. It is preferred that this step is performed as close to the transmission time as possible.

b) The destination(having internal congestion) may reduce ER to whatever rate it can support and/or set $\mathrm{CI}=1$ or $\mathrm{NI}=1$. A destination shall either set the $\mathrm{QL}$ and SN fields to zero, preserve these fields, of set them in accordance with ITU-T Recommendation I.371-draft. The octets may be set to $6 \mathrm{~A}$ (hexadecimal) or left unchanged.

2-3. If a forward RM cell is received by the destination while another turned around $\mathrm{RM}$ cell(on the same connection) is scheduled for in-rate transmission.

a) It is recommended that the contents of the old cell are overwritten by the contents of the new cell;

b) It is recommended that the old cell(after possibly having been overwritten) shall be sent out-of-rate; alternatively the old cell may be discarded or remain scheduled for in-rate transmission;

c) It is required that the new cell be scheduled for in-rate transmission.

2-4. Regardless of the alternatives chosen in destination behaviour \#3 above, the contents of an old cell shall be transmitted after the contents of a newer cell have transmitted.

2-5. A destination may generate a backward RM cell without having received a forward RM cell. The rate of these backward RM cells(including both in-rate or outof-rate) shall be limited to 10 cells/second, per connection. When a destination 
generates an $\mathrm{RM}$ cell it shall set either $\mathrm{CI}=1$ or $\mathrm{NI}=1$, shall set $\mathrm{BN}=1$, and shall set the direction to backward. The destination shall assign values to the various RM cell fields as specified for destination generated cells.

2-6. When a forward RM cell with CLP=1 is turned around it may be sent in-rate(with CLP=0) or out-of-rate(with CLP=1).

\section{SWITCH BEHIVIOUR}

3-1. A switch shall implement at least one of the following methods to control congestion at queuing points.

a) EFCI marking : The switch may set the EFCI state in the data cell headers;

b) Relative Rate Marking : The Switch may set $\mathrm{CI}=1$ or $\mathrm{NI}=1$ in forward and/or backward RM cells;

c) Explicit Rate Marking : The switch may reduce the ER field of forward and/or backward RM cells(Explicit Rate Marking);

d) VS/VD Control : The switch may segment the ABR control loop using a virtual source and destination.

3-2. A switch may generate a backward RM cell. The rate of these backward RM cells(including both in-rate and out-of-rate) shall be limited to 10 cells/second, per connection. When a switch generates an $\mathrm{RM}$ cell it shall set either $\mathrm{CI}=1$ or $\mathrm{BN}=1$, and shall set the direction to backward. The switch shall assign values to the various RM cell fields.

3-3. RM cells may be transmitted out of sequence with respect to data cells. Sequence integrity within the RM cell stream must be maintained.

3-4. For RM cells that transit a switch(ie., are received and then forwarded), the values of the various fields before the CRC-10 shall be unchanged except;

a) CI, NI, and may be modified as noted in $\# 1$ above

b) RA, QL and SN may be set in accordance with ITU-T Recommendation I.371draft. 
c) MCR may be corrected to the connection's MCR if the incoming MCR value is incorrect.

3-5. The switch may implement a use-it-or-lose-it policy an ACR to a value which approximates the actual cell transmission rate from the source. 


\section{APPENDIX-B : MARKOV MODULATED FLUID FLOW MODEL AND QUEUE LENGTH ANALSIS}

\section{INTRODUCTION}

The fluid flow modelling refers to continuous-space queues with continuous interarrival times. The arrival process is considered as a source of fluid flow generating a continuous stream of arrivals that is characterised by a flow rate, and departure as a continuous depletion of the waiting queue of a constant rate.

The fluid flow models are appropriate approximations to situations where the number of arrivals is relatively large so that an individual unit is by itself of little significance. The effect that an individual unit has on the overall arrival process is just as a drop of water in a fluid flow.

The Markov Modulated Fluid Flow (MMFF) is a suitable model for analysing traffic presented to a switch an ATM network. In ATM network, packet size is fixed in length (53bytes), and the transmission speeds are very high. Therefore, the effect of the transmission time of an individual cell is infinitesimal in the fluid flow model.

\section{MODEL AND QUEUE LENGTH ANALYSIS}

A birth-death process is a special case of Markov chain in which the process makes transitions only the neighbouring states of its current position. This restriction simplifies the treatment ant makes it an excellent model for queuing system.

Let a "birth" be an event signifying an increase in the population and a "death" be an event that signifies a decrease in the population and consider a sufficiently small interval of time $\delta \mathrm{t}$.

(1) Suppose the process $X(t)$ is in state 0 (off state)at time t. 
During the infinitesimal interval $(t, t+\delta t)$, the probability that $X(t)$ changes its state from 0 to 1 is $\lambda \delta t+o \delta t$ and the probability remains in state 0 is $1-\lambda \delta t+o \delta t$.

(2) Suppose the process $X(t)$ is in state 1 (on state) at time $t$.

During the infinitesimal interval $(t, t+\delta t)$, the probability that $X(t)$ changes its state from 1 to 0 is $\alpha \delta t$ to $\delta$ t and the probability remains in state 1 is $1-\alpha \delta t+o \delta t$.

(3) During the time $(t, t+\delta t)$, the probability more than one change of state occurs is oot.

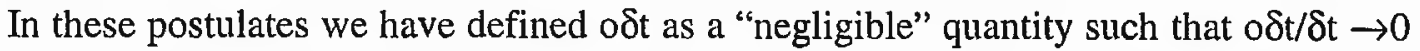
as $\delta t \rightarrow 0$, i.e., o $\delta t$ tends to zero much faster than $\delta t$. The buffer occupancy becomes a continuous random variable $x$. This is "fluid" in the fluid flow analysis. Each represents two state model and gives rise to the composite model of Fig. B-1.

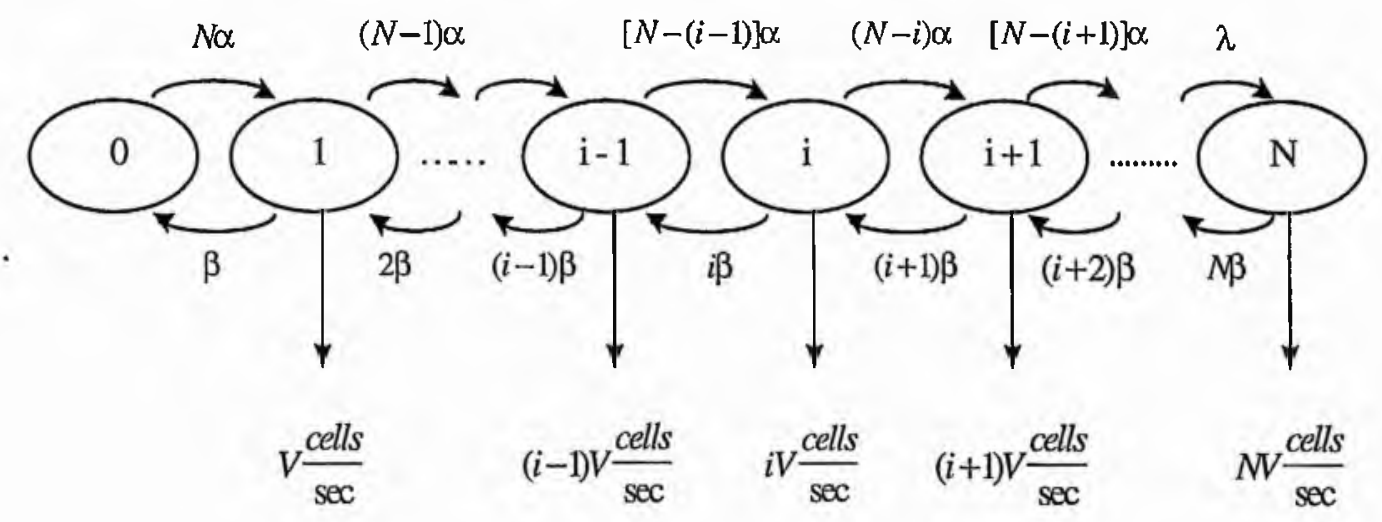

Fig. B-I A Birth-Death Model

To find the distribution $x$, we define $P i(t, x), 0 \leq i \leq N$, as the cumulative probability distribution at time $t$, which represents the probability that the buffer occupancy is less than or equal to $\mathrm{x}$ with $\mathrm{i}$ source on. The change in buffer size over an interval $\delta \mathrm{t}$ sec when the system is in state $\mathrm{i}$ will be $\delta \mathrm{x}=(\mathrm{iV}-\mathrm{C}) \delta \mathrm{t}$. 
The probability that the buffer occupancy is less than or equal to $\mathrm{x}$ with $\mathrm{i}$ source is given by the following equation

$$
\begin{aligned}
\operatorname{Pi}(t+\delta t, x)= & {[N-(i-1)] c i \delta t P i-1(t, x)+(i+1) \beta \delta t P i+1(t, x) } \\
& +\{1-[(N-1) \alpha+i \beta] \delta t\} P i+1[t, x-(i V-C) \delta t]+o \delta t
\end{aligned}
$$

This equation simplifies to the following equation

$$
\begin{aligned}
\frac{\partial P_{i}(x, t)}{\partial t}= & {[\mathrm{N}-(\mathrm{i}-1)] \alpha \mathrm{Pi}-1(\mathrm{t}, \mathrm{x})+(\mathrm{i}+1) \beta \mathrm{Pi}+1(\mathrm{t}, \mathrm{x}) } \\
& -[(\mathrm{N}-\mathrm{i}) \alpha+\mathrm{i} \beta] \mathrm{Pi}(\mathrm{t}, \mathrm{x})-(\mathrm{iV}-\mathrm{C}) \frac{\partial P_{i}(t, x)}{\partial x}
\end{aligned}
$$

As time goes on, the system assumes to be in the stationary state so that $\frac{\partial P_{i}(x, t)}{\partial t}=0$ and $\operatorname{Pi}(t, x) \rightarrow \operatorname{Pi}(x)$. So, the equation (B-2) becomes as follows

$$
(\mathrm{iV}-\mathrm{C}) \frac{d P_{i}(x)}{d x}=[\mathrm{N}-(\mathrm{i}-1)] \alpha \mathrm{Pi}-1(\mathrm{x})-[(\mathrm{N}-\mathrm{i}) \alpha+\mathrm{i} \beta] \mathrm{Pi}(\mathrm{x})+(\mathrm{i}+1) \beta \mathrm{Pi}+1(\mathrm{x})
$$

where $0 \leq \mathrm{i} \leq \mathrm{N}$, with $\mathrm{P}-1(\mathrm{x})=\mathrm{P} \mathrm{N}+1(\mathrm{x})=0$

By factoring the parameter $V$ out of left-hand side and $\beta$ out of right-hand side, we get a normalised form of equation(B-2)

$$
\frac{V}{\beta}\left(\mathrm{i}-\frac{C}{V}\right) \frac{d P_{i}(x)}{d x}=[\mathrm{N}-(\mathrm{i}-1)] \frac{\alpha}{\beta} \mathrm{Pi}-1(\mathrm{x})-\left[\mathrm{i}+(\mathrm{N}-\mathrm{i}) \frac{\alpha}{\beta}\right] \mathrm{Pi}(\mathrm{x})+(\mathrm{i}+1) \mathrm{Pi}+1(\mathrm{x})(\mathrm{B}-4)
$$

The solution of this equation is obtained by rewriting it as below 


$$
\begin{gathered}
-\frac{V}{\beta} \frac{C}{V} \frac{d P_{0}(x)}{d x}=-\mathrm{N} \frac{\alpha}{\beta} \mathrm{P} 0(\mathrm{x})+\mathrm{P} 1(\mathrm{x}) \\
\frac{V}{\beta}\left(1-\frac{C}{V}\right) \frac{d P_{1}(x)}{d x}=\mathrm{N} \frac{\alpha}{\beta} \mathrm{P} 0(\mathrm{x})-\left[(\mathrm{N}-1) \frac{\alpha}{\beta}+1\right] \mathrm{P} 1(\mathrm{x})+2 \mathrm{P} 2(\mathrm{x}) \\
\frac{V}{\beta}\left(2-\frac{C}{V}\right) \frac{d P_{2}(x)}{d x}=(\mathrm{N}-1) \frac{\alpha}{\beta} \mathrm{P} 1(\mathrm{x})-\left[(\mathrm{N}-2) \frac{\alpha}{\beta}+2\right] \mathrm{P} 2(\mathrm{x})+3 \mathrm{P} 3(\mathrm{x}) \\
\cdot \\
\frac{V}{\beta}\left(\mathrm{N}-\frac{C}{V}\right) \frac{d P_{N}(x)}{d x}=\frac{\alpha}{\beta} \mathrm{PN}-1(\mathrm{x})-\mathrm{NPN}(\mathrm{x})
\end{gathered}
$$

If we define the $(\mathrm{N}+1)$ elements row vector

$$
P(x)=[P 0(x), P 1(x), \ldots \ldots, P N(x)]
$$

And then the equation (4-8) may be written by

$$
\frac{V}{\beta} \frac{d P(x)}{d x} \mathrm{D}=\mathrm{P}(\mathrm{x}) \mathrm{M}
$$

with $\mathrm{D}$ an $(\mathrm{N}+1) \times(\mathrm{N}+1)$ diagonal matrix defined as

$$
\mathrm{D}=\operatorname{diag}[-\mathrm{C} / \mathrm{V},(1-\mathrm{C} / \mathrm{N}), \ldots,(\mathrm{N}-\mathrm{C} / \mathrm{V})]
$$

The $(\mathrm{N}+1) \times(\mathrm{N}+1)$ matrix $\mathrm{M}$, whose elements represent the transition rates between states with row elements summing to 0 , is called the infinitesimal generating matrix of the underlying Markov chain and is given by 


$$
\mathrm{M}=\left[\begin{array}{ccccc}
-N \frac{\alpha}{\beta} & N \frac{\alpha}{\beta} & 0 & \cdot \\
1 & -\left[(N-1) \frac{\alpha}{\beta}+1\right] & (N-1) \frac{\alpha}{\beta} & \cdot \\
0 & 2 & -\left[(N-2) \frac{\alpha}{\beta}+2\right] & \cdot & \cdot \\
0 & 0 & 3 & \cdot & \cdot \\
\cdot & \cdot & \cdot & \cdot \\
\cdot & \cdot & \cdot & \cdot & \cdot
\end{array}\right]
$$

We can rewrite equation (B-6)

$$
\frac{d P(x)}{d x}=\mathrm{P}(\mathrm{x}) \mathrm{M}
$$

We define that the eigenvalues of $(\mathrm{N}+1)$ matrix $\mathrm{M}_{D^{-1}}$ be $\mathrm{zi}$, the corresponding vectors be $\Omega i$, the $(\mathrm{N}+1)$ coefficients be $a_{i}$.

The general solution this equation is given by

$$
\mathrm{P}(\mathrm{x})=\sum_{i=0}^{N} a_{i} P_{i} e^{Z_{i,}^{\frac{\beta}{\gamma}}}
$$

with zi the ith eigenvalue, $\Omega \mathrm{i}$ the corresponding eigenvector given as the solution to the eigenvector equation

$$
\operatorname{zi} \Omega i \mathrm{D} \frac{V}{\beta}=\Omega \mathrm{j} \mathrm{M}
$$

The survivor function is defined as $G(x)=1-P(x)$, we can get the approximation value by the following equation, 


$$
\begin{aligned}
\mathrm{G}(\mathrm{x}) & =1-\mathrm{P}(\mathrm{x})=-\sum_{i: r e\left[Z_{i}^{<}<0\right]} a_{i}\left[\sum_{j=0}^{N} \Omega_{i j}\right] e^{Z_{i} \frac{\beta}{V} x} \\
& \sim \mathrm{AN} \rho^{N} e^{-\frac{\beta}{v} r x}
\end{aligned}
$$

where $r=(1-\rho)(1+\alpha / \beta) /(1-\mathrm{C} / \mathrm{NV}), \rho=\mathrm{NPV} / \mathrm{C}=\mathrm{N} \lambda / \mathrm{C}, \mathrm{P}=\alpha /(\alpha+\beta)$

When the utilisation $\rho$ is relatively closed to 1 , in which $A N>1, \rho^{N}<1$ compensate for one another to some extent, the approximation value of $A N \rho^{N}$ in loss probability $G(x)$ is 1 .

Finally, we get the approximation of loss probability of a system and its queue length,

$$
\begin{aligned}
& \mathrm{PL}=e^{-\frac{\beta}{V} r x}, \\
& \mathrm{x}=\lambda\left(\frac{\alpha+\beta}{\alpha \beta}\right)\left(\frac{1}{r}\right)(\ln 1 / \mathrm{PL})
\end{aligned}
$$

